University of Louisville

ThinkIR: The University of Louisville's Institutional Repository

\title{
Teacher-student relationships during adolescence : the role of parental involvement, behavioral characteristics, gender, and income.
}

Amanda Jeane Wyrick

University of Louisville

Follow this and additional works at: https://ir.library.louisville.edu/etd

\section{Recommended Citation}

Wyrick, Amanda Jeane, "Teacher-student relationships during adolescence : the role of parental involvement, behavioral characteristics, gender, and income." (2011). Electronic Theses and Dissertations. Paper 1599.

https://doi.org/10.18297/etd/1599

This Doctoral Dissertation is brought to you for free and open access by ThinkIR: The University of Louisville's Institutional Repository. It has been accepted for inclusion in Electronic Theses and Dissertations by an authorized administrator of ThinkIR: The University of Louisville's Institutional Repository. This title appears here courtesy of the author, who has retained all other copyrights. For more information, please contact thinkir@louisville.edu. 
TEACHER-STUDENT RELATIONSHIPS DURING ADOLESCENCE:

THE ROLE OF PARENTAL INVOLVEMENT, BEHAVIORAL CHARACTERISTICS, GENDER, AND INCOME

\title{
By
}

Amanda Jeane Wyrick

B.A., Bellarmine University, 2003

M.Ed., University of Louisville, 2006

\author{
A Dissertation \\ Submitted to the Faculty of the \\ College of Education and Human Development of the University of Louisville \\ in Partial Fulfillment of the Requirements \\ for the Degree of
}

Doctor of Philosophy

Department of Educational and Counseling Psychology

University of Louisville

Louisville, Kentucky

August 2011 
TEACHER-STUDENT RELATIONSHIPS DURING ADOLESCENCE: THE ROLE OF

PARENTAL INVOLVEMENT, BEHAVIORAL CHARACTERISTICS, GENDER, AND INCOME

\section{By}

Amanda Jeane Wyrick

B.A., Bellarmine University, 2003

M.Ed., University of Louisville, 2006

A Dissertation Approved On

May 2, 2011

By the following Dissertation Committee:

(Dissertation Chair)

Peter Alter

Linda Shapiro 


\begin{abstract}
TEACHER-STUDENT RELATIONSHIPS DURING ADOLESCENCE: THE ROLE OF PARENTAL INVOLVEMENT, BEHAVIORAL CHARACTERISTICS, GENDER, AND INCOME Amanda J. Wyrick
\end{abstract}

May 2, 2011

This dissertation provides an examination of contributing factors to high quality teacherstudent relationships during adolescence. High quality teacher-student relationships have been linked to better academic, emotional, and social functioning for students in elementary, middle, and high school. While the importance of teacher-student relationships is well documented, less is know about contributors to the relationship, especially during adolescence. Previous research has identified that in younger populations a student's gender, income, behavioral characteristics, and parental involvement can influence the nature of the teacher-student relationship. This dissertation provides an important extension of contributing factors into the adolescent age group, where teacher-student relationships offer an additional source of adult support and positively impact bonding to school norms and emotional functioning.

This dissertation uses 820 participants from the NICHD Study of Early Child Care and Youth Development. Collection of data for use in this study occurred in 2006, which adolescents were 15 years of age. Data were collected from adolescents via questionnaires in the lab and home and from parents in the home only. Demographic data 
included gender and income. Additional data was collected from measures of teacher relationships, maternal and paternal involvement, and behavioral problems. A series of hierarchical linear regression analyses were conducted to determine the extent to which parental involvement and behavioral characteristics predict the quality of teacher-student relationships as well as to what extent behavioral characteristics and income moderate the relationship between parental involvement and teacher-student relationship quality.

Results from this dissertation indicate that both gender and income are significantly related to teacher-student relationship quality, with girls experiencing more high quality relationships. Income results were mixed. Students from high-income homes experienced more quality in overall relationships with teachers while low-income students endorsed better individual teacher relationships. Furthermore, ratings of both maternal and paternal involvement were significantly related to higher ratings of teacher-student relationship quality. Taken together, research indicates that parents who are involved in a student's education influence the relationship the child has with his/her teacher, thereby improving academic success and emotional functioning. The dissertation concludes with implications for educators, schools, and counselors. 


\section{TABLE OF CONTENTS}

\section{PAGE}

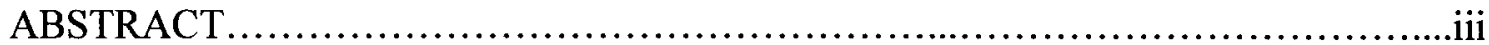

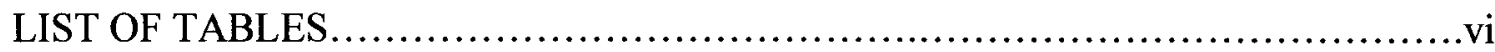

CHAPTER 1: INTRODUCTION ....................................................

CHAPTER 2: LITERATURE REVIEW ............................................

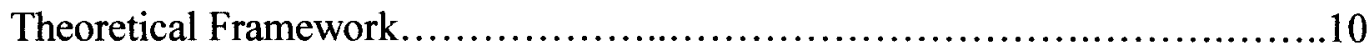

Teacher-Student Relationships........................................... 14

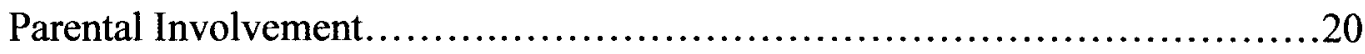

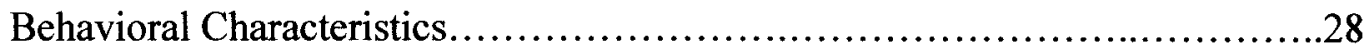

Gender...................................................................

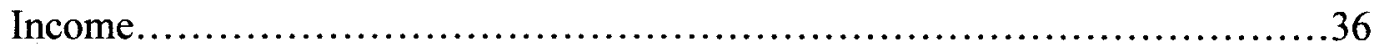

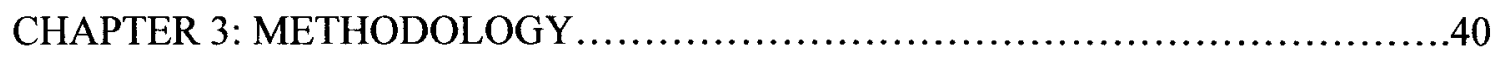

Participants............................................................... 40

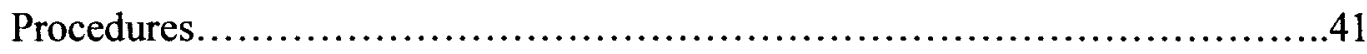

Measures.....................................................................

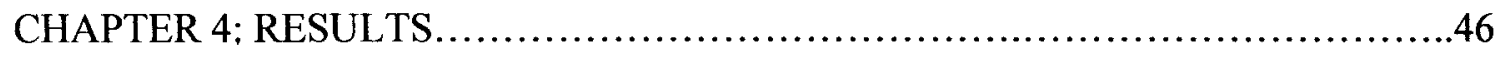

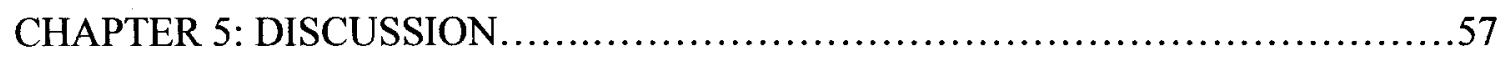

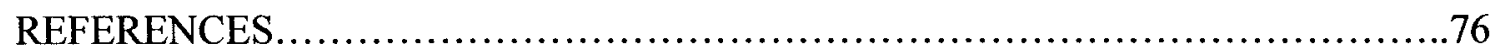

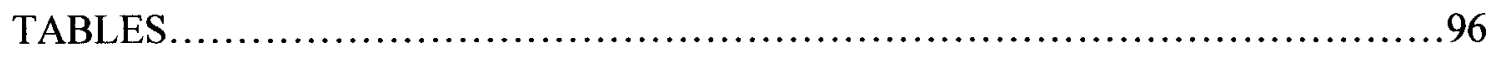

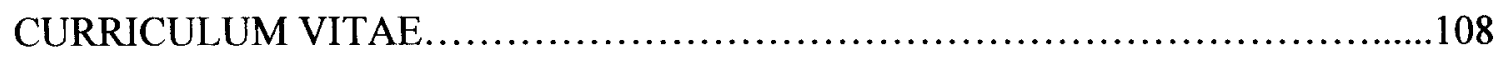




\section{LIST OF TABLES}

PAGE

TABLE

1. Means and Standard Deviations for Study Variables............................... 96

2.Intercorrelations for Relations Between Student Variables and Teacher Relationship Quality...................................................................97

3. Hierarchical Regression Analyses Predicting Student Teacher Relationship Quality from Gender, Income, and Parental Involvement.................................98

4. Hierarchical Regression Analyses Predicting Connection with Teachers From Gender, Income, and Parental Involvement.............................................99

5. Hierarchical Regression Analyses Predicting Student Teacher Relationship Quality From Gender, Income, Internalizing and Externalizing Problems.....................100

6. Hierarchical Regression Analyses Predicting Connections with Teachers From Gender, Income, Internalizing, and Externalizing Problems.

7. Hierarchical Regression Analyses Predicting Student Teacher Relationship Quality

From Gender, Income, Maternal Involvement, and Behavioral Characteristics..........102

8. Hierarchical Regression Analyses Predicting Student Teacher Relationship Quality

From Gender, Income, Parental Involvement, and Behavioral Characteristics.

9. Hierarchical Regression Analyses Predicting Connection with Teachers From Gender, Income, Maternal Involvement, and Behavioral Characteristics .104

10. Hierarchical Regression Analyses Predicting Connection with Teachers From Gender, Income, Paternal Involvement, and Behavioral Characteristics.

11. Hierarchical Regression Analyses Predicting Student Teacher Relationship Quality

From Gender, Income, Parental Involvement, and Income.

12. Hierarchical Regression Analyses Predicting Connection with Teachers From Gender, Income, Parental Involvement, and Income. 


\section{CHAPTER 1}

\section{INTRODUCTION}

\section{Statement of the Problem}

Adolescence is a phase of development in which the struggle between autonomy and attachment to caregivers moves to center stage (McElhaney, Allen, Stephenson, \& Hare, 2009). Successful development depends on caregivers' and adolescents' abilities to balance close connections and autonomous behaviors such as increasing knowledge of and mastery over various environments (McElhaney et al.). The combination of autonomy and relatedness allows for an adolescent to establish identity as well as improve the relationship with the caregiver (McElhaney et al.). The establishment of an adolescent's own identity also means he or she may begin to rely more heavily on relationships outside of their family of origin (Vieno, Perkins, Smith \& Santinello, 2005). q A close relationship with a teacher has been connected to children's higher academic ratings (Pianta \& Stuhlman, 2004), increased self-directed behavior in the classroom (Birch\& Ladd, 1997), and increased compliance with classroom rules (Ladd, Birch, \& Buhs, 1999). During adolescence, a highly supportive relationship between teacher and student is connected to better outcomes in academics and behaviors (i.e., less risk taking, fewer suspensions, decreased depression) (LaRusso, Romer, \& Selman, 2008; Crosnoe, Johnson, \& Elder, 2004; Suldo et al., 2009; Demaray, Malecki, Reueger, Brown, \& Summers, 2009; Ellonen, Kaariainen, \& Autio, 2008). 
Crosnoe et al. (2004) found that an adolescent's indication of a positive relationship with a teacher was related to improvement in the quality of academic functioning. There is also evidence supporting a link between adolescents' feeling higher levels of support by teachers and in turn, feeling better about themselves (Demaray et al., 2009; Suldo et al., 2009). Support and encouragement in a relationship with a teacher is also associated with lower levels of depressive symptoms and behavior problems for adolescents (Crosnoe et al., 2004; Ellonen et al., 2008). The relationship between a teacher and a student can also influence student behavior by impacting the student's feelings towards school in general. LaRusso et al. (2008) found that sensitive and supportive teachers were associated with an adolescent's sense of respect and belonging in the school, which in turn is related to less drug use and lower levels of depressive symptoms.

To gain a full understanding of the relationship between a teacher and a student, it is important to examine variables that contribute to a high quality, supportive relationship. In the context of a bioecological model of development, characteristics of both the teacher and the student can contribute to the development of high quality relationships. Students bring biological characteristics (i.e., gender, ethnicity), behavioral characteristics (i.e., temperament, emotional and behavioral disorders), and environmental characteristics (i.e., parent involvement, income) to the classroom that in turn affects their relationships with their teachers and their school success (Bronfenbrenner \& Morris, 1998).

Children also bring a history of relationships to the classroom that influences the quality of relationships with their teachers. According to Bowlby's attachment theory, 
children can develop either secure or insecure attachments with their caregivers. A securely attached child uses the caregiver as a base to explore the world and reestablish contact after a separation. A child with an insecure attachment style does not use his or her caregiver as a secure base and has difficulty reuniting after separation (Bowlby, 1969, 1982).

Research suggests the type of attachment influences a child's internal working model, which thereby affects the quality of relationships with subsequent caregivers, including teachers (Zionts, 2005). A child who is securely attached has a positive internal working model that promotes increased self-worth and security within other relationships. Young children with insecure styles of attachment develop less positive internal working models. As such, they experience less closeness with their teachers than those with secure styles of attachment (Rydell, Bohlin, \& Thorell, 2005). O'Connor and McCartney (2006) found that kindergarten and first grade children with insecure attachment styles had lower quality teacher student relationships. They postulated that attachment most likely impacts the student teacher relationship through behavior problems (e.g., aggression and anxiety) of the child. Furthermore, they found that children with secure attachment styles had more positive relationships with their teachers. In regards to environmental characteristics, the extent to which parents are involved in their children's education is an important predictor of numerous school outcomes (Gregory \& Weinstein, 2004; Hoover-Dempsey \& Sandler, 1995; Pomerantz, Moorman, \& Litwack, 2007). This is consistent with the bioecological model of development as it exemplifies the important role of proximal processes between microsystems. While few studies have linked parental involvement to the quality of the 
child's relationship to the teacher, many studies have shown positive outcomes in other areas of school success. For example, when adolescents feel that their parents are more connected to them and monitor them more, they experience higher achievement in mathematics (Gregory \& Weinstein, 2004). In their model of parental involvement Hoover-Dempsey and Sandler (1995) also stated that parents who are involved in their children's education enhanced knowledge and skill development by reinforcing values related to school success, modeling school related behaviors (i.e. reading), and actually assisting with schoolwork.

In addition to better academic functioning, parental involvement is linked to improved emotional outcomes for children. Children with parents who create an atmosphere that values the importance of involvement in the school process (e.g., verbal reinforcement for school achievement or help with homework) feel more efficacious in school related tasks and thereby have more positive emotions related to school (HooverDempsey \& Sandler, 1995). In a comprehensive review of literature, Pomerantz et al. (2007) linked parental involvement to the following emotional outcomes: increased selfesteem; increased emotion regulation skills; enhanced social functioning with peers; decreased negative emotions such as depression and anxiety; and a decrease in behavior problems like delinquency and substance abuse.

The studies that have shown a relationship between parental involvement and teacher-student relationships provide additional evidence for the importance of involvement from parents. Higher levels of parental involvement have been linked to improved student-teacher relationships in elementary school (Deraring, Kreider, \& Weiss, 2008; Wyrick \& Rudasill, 2009) and during the transition to high school (Chen \& 
Gregory, 2010). Furthermore, Mantzicopoulos (2005) found that less positive parent and community relationships with the school contributed to higher levels of conflict between children and teachers.

In addition to environmental factors such as parent involvement, children also bring internal factors, such as behavioral characteristics, to the relationships they build with teachers. When students were rated as having higher levels of externalizing and internalizing problems in third through fifth grade there was a strong positive association with the level of conflict these children experienced with their teachers (Murray \& Murray 2004). O'Connor and McCartney (2006) also found that teachers rate their relationships with children with behavioral problems as lower in quality. Furthermore, specific behaviors such as low levels of effortful control (i.e., ability to control behavioral responses) (Rudasill \& Rimm-Kaufmann, 2009) and increased hyperactivity (Mantzicopoulos, 2005) have been associated with higher levels of conflict with the teacher. In addition, Ladd et al. (1999) found that children with antisocial behavioral styles were rated as having a more conflictual relationship with their teacher.

Other factors that have been linked to the quality of the relationship between teacher and student are family income and student gender. In regards to income, the quality of relationships between teachers and students are lower in preschool classrooms where $60 \%$ or more of the students live below poverty level (Pianta et al., 2005). Children from lower income families also experienced more conflict and less closeness with teachers (Wyrick \& Rudasill, 2009). Conversely, when children in kindergarten have socioeconomic advantages, relationships with teachers tend to be closer (Ladd et al., 1999). Gender is related to teacher-student relationship quality in that girls have 
consistently higher degrees of closeness and less conflict with their teachers than their male counterparts (Baker, 2006; Birch \& Ladd, 1997). Boys on the other hand, experience more conflict and less closeness (Hughes et al., 2001; Saft \& Pianta, 2001), which in turn influences academic outcomes throughout elementary and middle school (Hamre \& Pianta, 2001).

The primary purpose of this study is to join together several lines of research to examine student-teacher relationship development in adolescence. As noted, some research has examined teacher-student relationships with adolescents, but little is known about what predicts the quality of the relationship for this age group. As adolescents deal with identity development and form new relationships to prepare them for adulthood, they must also exist within a school system that expects a degree of conformity to norms. Difficulty with bonding to school norms and adjusting to academic demands during high school can lead to a lack of competence during adulthood (McElhaney et al., 2009). Yet research shows that highly supportive teacher-student relationships can assist adolescents with navigation of the school environment. Given the importance of teachers as an attachment figure for adolescents, more research is needed to determine the factors that contribute to a supportive teacher-student relationship.

The first goal of this study is to build upon current teacher-student relationship literature by focusing on the under studied population of adolescents. The second goal is to examine behavioral characteristics and parent involvement as predictors of students' perceptions of teacher support during high school. The third goal of this study is to examine the role of behavioral and environmental characteristics as moderators of the associations between parent involvement and student perceived teacher support. 
Given my examination of the literature I have the following hypotheses. First, gender and income will have main effects on the teacher-student relationship, with girls and students with higher incomes reporting higher levels of teacher support. Second, adolescents with higher ratings of internalizing and externalizing problems will rate their relationships with teachers as less supportive. Third, as adolescents' report of parent involvement increases, so will the reported amount of teacher support. Finally, behavioral characteristics and environmental characteristics (i.e., income) of the adolescent will moderate the associations between parent involvement and student perceived teacher support. 


\section{CHAPTER 2}

\section{REVIEW OF THE LITERATURE}

\section{Adolescent and Teacher Relationships}

The relationship between students and their teachers is a critical component of academic, social, behavioral, and emotional development across the span of the educational journey (Baker, 2006; Crosnoe et al., 2004; Demaray et al., 2009; Hamre \& Pianta, 2005; Hughes, Cavell \& Wilson, 2001; Ladd et al., 1999; Pianta \& Stuhlman, 2004). Research conceptualizes this relationship in different ways depending on the age of the student. For elementary students, teacher relationships are beneficial when there are high degrees of warmth and closeness (Pianta \& Stuhlman) and low levels of conflict (Pianta, 1999). For adolescents in middle and high school, aspects of the relationship that become important include belonging (i.e., feeling close to teachers at the school) (McNeely \& Falci, 2004), respect (LaRusso et al., 2008) and bonding (i.e., getting along with the teacher and feeling cared for by the teacher) (Crosnoe et al.). These elements are often combined to describe a construct known as teacher support (Brewster \& Bowen, 2004; Metheny, McWhirter \& O’Neil, 2008; Reddy, Rhodes \& Mulhall, 2003; Suldo et al., 2009). The degree of support within the relationship can be based on teacher perceptions or student perceptions. While the teacher typically rates relationship quality characteristics of closeness and conflict during elementary school, during adolescence teacher support is typically evaluated from the adolescent's perspective. Indeed, research supports the use of the adolescent's perception as an important factor in determining 
whether or not teacher support is a positive influence on cognitive and emotional development (Cohen, Underwood \& Gottlieb, 2000).

To gain a full understanding of the importance of teacher support during adolescence, it is helpful to examine research on school bonding and connectedness (Catalano, Haggerty, Oesterle, Fleming \& Hawkins, 2004; Faircloth \& Hamm, 2005; Resneck et al., 1997). School bonding and connectedness typically address both the relationships a student has with those at school and an investment in and commitment to the school (Catalano et al., 2004). Teacher support, therefore, is a measure of school bonding and connectedness and is related to a student's sense of community (i.e., being accepted, receiving help when needed, and feeling a sense of belonging) within the school (Vieno et al., 2005).

For the purpose of this study, student-teacher relationships are examined in the context of teacher support. Teacher support encompasses the elements of bonding, social support (i.e., seeking out the teacher for personal problems), instrumental support (i.e., teacher helps student get things done), and shared activities (Furman, 1996; Furman \& Buhrmester, 1985). In addition to examining literature directly related to bonding with a teacher, a broad and comprehensive understanding of teacher support must include research on younger children where the relationship is measured in terms of closeness and conflict. Despite the variability in terminology and age of student, the effect of highly supportive teachers is important for students' academic, social, emotional, and behavioral development. 


\section{Theoretical Framework}

Two theoretical models inform this study. They are the bioecological model of human development (Bronfenbrenner and Morris, 1998) and attachment theory (Bowlby, 1969,1982). In the bioecological model, individuals develop within four types of systems: micro, meso, exo, and macro. The microsystem encompasses activities, social roles, and interpersonal relationships that are directly experienced by the developing person. These include interactions the adolescent has at home, at school, or with peers. The mesosystem is comprised of interactions between different microsystems. A common example of interactions between systems is found between the home and school. The exosystem is made up of processes that take place between two or more settings, one of which does not directly involve the developing adolescent. For example, the exosystem would be used to describe the influence of a teacher's home life on his/her interactions in the classroom with the adolescent. Finally, the macrosystem describes the larger cultural context in which an individual develops. Examples of the culture include things such as the political climate and socioeconomic status (Bronfenbrenner and Morris, 1998).

According to the bioecological model, the interactions between the individual and the environment are the primary mechanisms of human development and are known as proximal processes. In adolescence, some primary proximal processes are interactions between an adolescent and a teacher and an adolescent and a parent. The nature of these processes is influenced by characteristics of the adolescent, the environment, and the time period in which the processes take place. According to Bronfenbrenner, three types of individual characteristics influence proximal processes: dispositions (e.g., temperament); resources of ability, experience, knowledge, and skill; and demand characteristics (i.e., 
aspects of the adolescent's personality that invite or discourage reactions from the environment). Proximal processes are reciprocal in nature, such that an adolescent's characteristics influence the environment and the environment influences the characteristics of the adolescent. In addition, the subjective perception of the environment by the adolescent can influence development in the same way as the actual concrete experience of the environment (Bronfenbrenner \& Morris, 1998). For example, an adolescent's perception that a teacher will be supportive may influence development the same as actual experiences of provided support.

Positioned in the context of the bioecological model of development, attachment theory focuses more specifically on interactions, or proximal processes, between individuals and others in the environment. Attachment theory describes the ability of human beings to form strong affectional bonds to others. During the first few years of development, a child forms an attachment to a primary caregiver. This attachment can either be secure or insecure. A secure attachment means that the child uses the caregiver as a secure base and feels safe and supported when engaging in new tasks. Securely attached adolescents may use parents as a secure base to explore new settings and return to them when limits of competence are reached (McElhaney et al., 2009). An example would be when an adolescent joins a new peer group and returns to the parent to ask for assistance in responding to peer pressure.

An insecure attachment is seen in children and adolescents who do not return to the primary caregiver to receive support and love when something upsetting has occurred. The child may either avoid the caregiver (insecure-avoidant) or cry for the caregiver but fight against comfort when it is offered (insecure-resistant). There is a 
fourth type of attachment known as insecure-disorganized which describes a child that does not display consistent reactions to the caregiver. The style of attachment a child has to his/her primary caregiver influences other interpersonal relationships through the development of an internal working model, which informs the child about his/her selfworth as well as the dependability of others to provide care. The internal working model may be positive in that children feel safe entering into relationships with others and believe that others will be supportive when needed. Conversely, the internal working model may be negative, meaning that children are skeptical about the dependability of others and may reject others or become anxious when entering into new relationships. The ability of individuals to form attachment bonds with more than one significant person across the lifespan is known as multiple attachment relationships (Bowlby, 1969, 1982). Attachment security within multiple relationships leads to more social competence and acceptance, and overall higher relationship quality with others (McElhaney et al., 2009).

The theoretical underpinnings of the bioecological model and attachment theory both inform and support the importance of this research study. First, this study examines the role of parent involvement in school on the relationship between teacher and student. The bioecological model supports the examination of mesosystems (i.e., the interaction between two systems within which the adolescent exists) for a full understanding of adolescent development (Bronfenbrenner \& Morris, 1998). Secondly, attachment theory gives support for examining the interactions between teachers and students. For example, teachers who serve as a secure base for a child can provide emotional support that facilitates successful adaptation to the school environment (Zionts, 2005). Furthermore, 
teachers are viewed as the primary source of non-parental role models and attachment figures for adolescents (Eccles \& Roeser, 2009). Given the fact that secure attachments are critical for healthy development, the attachment an adolescent has with his/her teacher becomes even more important for those adolescents that do not have secure attachments with other caregivers (Eccles \& Roeser, 2009). Lastly, the bioecological model supports the examination of the influence of behavioral characteristics, gender, and income on the interactions between teachers and students. Bronfenbrenner and Morris (1998) state that characteristics of the person (i.e., behavior and gender) can influence the proximal processes that are important to development. Furthermore, the examination of income as a predictor variable is supported by the inclusion of the exosystem in the bioecological model. In this system, the financial situation of the adolescent's family can influence another realm of development in which the adolescent is a key contributor (i.e., school context).

This study has two goals. First, this study is designed to examine environmental characteristics (i.e., parent involvement and income) and child characteristics (i.e., gender and internalizing and externalizing problems) as predictors of relationship quality with teachers (i.e., teacher support). Second, this study will investigate the extent to which specific child (i.e., internalizing and externalizing problems) and environmental characteristics (income) moderate the relationship between adolescents' perceptions of parent involvement and teacher support. The ability for an adolescent to have supportive relationships with teachers is based not only on his/her characteristics, but the other contexts in which development occurs. It is the context of the home and the level of 
support and involvement of the parents that can influence the amount of support an adolescent receives from a teacher.

\section{Teacher-Student Relationships and Academic Outcomes}

In studies of young children, student-teacher relationships have primarily been measured by teacher's perceptions of the quality of their relationships with students and have been related to academic outcomes. For example, first grade teachers rated student achievement higher for those students with whom they reported a close relationship and rated student achievement lower if the relationship was classified as conflictual (Pianta \& Stuhlman, 2004). More positive teacher-child relationship scores have also been found to predict higher scores on age-appropriate concepts (i.e., size, time, and classification principles) and language tests for preschool children (Pianta, Nimetz \& Bennett, 1997). Further support for the importance of teacher-student relationship quality and school achievement is documented in findings by Hughes and Kwok (2007), where first grade students' gains in reading scores were related to better relationships with teachers.

High levels of teacher support can influence student success by promoting the student's adoption of classroom norms and goals that a teacher values. For example, children at high risk for academic failure (i.e., emotional/behavioral problems, academic problems) experienced higher academic achievement in classrooms where teachers offered more emotional support (Hamre \& Pianta, 2005). The authors hypothesized that this may be attributed to the fact that the positive classroom climate helped students enjoy the class and, therefore, increased the likelihood that they would pursue teacher goals such as engagement in academics (Hamre \& Pianta). Ladd et al. (1999) suggests that high quality relationships with teachers may improve academic success because the 
relationship promotes a more independent and cooperative style of classroom participation. While the exact nature of how positive teacher-student relationships come to affect academic outcomes remains debatable, the fact that the relationships are important is hard to deny. Hamre and Pianta's (2001) research solidifies this point by showing kindergarten teacher perceptions of higher conflict with male students were significant predictors of poor academic outcomes in math and reading from first to eighth grade for those students.

Studies examining elements of belonging and bonding among adolescents and teachers have shown an association between middle and high school students' feelings of bonding and better academic skills and higher levels of academic achievement (Catalano et al., 2004). Furthermore, when high school students evaluated their specific level of bonding with teachers, higher ratings on elements such as feeling cared for and supported were positively related to the students' efficacy beliefs, valuing of school, and GPA (Faircloth \& Hamm, 2004). Adolescents' sense of bonding with teachers (i.e., feeling cared for by teachers, getting along with teachers, and belief that teachers treated them fairly) in grades 7-12 was related to higher levels of achievement in math, science, English, and social studies (Crosnoe et al., 2004). An extensive review of literature on teacher-student relationships during adolescence showed the level of bonding with a teacher can also serve as a protective factor against dropping out of high school (Davis, 2003). In addition, this review suggests that, while the importance of a relationship with a teacher may change or diminish in quality during middle school, it is still related to academic outcomes including a higher GPA, increased task focus on academic goals, and more overall engagement with school (Davis). Similarly, Van Ryzin, Gravely and Roseth 
(2009) found that teacher support during middle school was related to more engagement in learning and subsequently better psychological adjustment (i.e., orientation towards goals and perceived ability to accomplish goals).

\section{Teacher-Student Relationships and Social, Emotional, and Behavioral Outcomes}

A highly supportive relationship with a teacher can enhance positive social, emotional, and behavioral development during elementary, middle, and high school. Baker (2006) found that the quality of the teacher-student relationship during elementary school was a positive predictor of behavioral indicators (i.e., social skills) related to school success. Support and closeness in teacher-student relationships have also been associated with higher levels of social competency in the areas of frustration tolerance for kindergarteners (Pianta et al., 1997), and cooperation, assertion, responsibility, and selfcontrol in preschool through first grade (Pianta \& Stuhlman, 2004). Furthermore, a highly supportive teacher-student relationship has been linked to lower levels of maladaptive social behaviors such as aggression in third and fourth grade children (Meehan, Hughes \& Cavell, 2003), and improved social competence for kindergarten, first, third, and fourth grade students (Hughes et al., 2001; Pianta, Nimetz \& Bennett, 1997; Pianta \& Stuhlman, 2004). Hughes et al. (2001) found that third and fourth grade students are more likely to rate their peers as having higher social competencies, such as being a leader and being liked, if they perceived the student as having high levels of teacher support. This adds a unique perspective to the literature, demonstrating that teacher support can go beyond direct student effects to influence how peers perceive each other in the classroom.

Research suggests that the conflict a student experiences with a teacher can have a more significant impact on the student's development than the level of closeness. This 
may be due to the fact that relational conflict is more stable across teachers, whereas closeness with a teacher may be more specific to the fit between a student and teacher's style of interaction (Howes et al., 2000; O’Connor \& McCartney, 2006; Pianta \& Stuhlman, 2004; Rudasill, 2011). The fact that a student with a conflictual style of interaction with one teacher is likely to have conflict with other teachers suggests that the effects of conflict on development compound with time. For example, Pianta and Stuhlman (2004) found that teacher ratings of conflict from preschool to first grade remained stable and were significant predictors for teacher ratings of externalizing and internalizing behaviors as well as lower ratings of social competencies. Furthermore, Pianta, Sternberg, and Rollins (1995) found that poor quality relationships with teachers in kindergarten were associated with higher levels of behavior problems and lower levels of social competence, and these ratings were consistent with those provided by second grade teachers. In other research, Birch and Ladd (1997) showed an association between kindergarten students' conflict with teachers and school outcomes such as liking school less, being less compliant with classroom rules, and being more avoidant of school. Elementary school age children who feel as though they lack emotional support and involvement with teachers may experience multiple negative consequences that can profoundly impact school functioning, such as higher rates of delinquent behavior and more conduct problems (Murray \& Greenberg, 2000).

Literature documents the effects of supportive teacher relationships on social, emotional, and behavioral outcomes in adolescent years as well. The onset of adolescence highlights the importance of health-related behaviors in youth such as drug use and sexual activity. Teacher support during adolescence (i.e., $7^{\text {th }}-12^{\text {th }}$ grade) can serve as a 
protective factor against dangerous health behaviors such as smoking, getting drunk, marijuana use, suicidal ideation, first sexual intercourse, and weapon-related violence (McNeely \& Falci, 2004). In a younger sample, Rudasill, Reio, Stipanovic and Taylor (2010) found that more teacher-rated conflict in $4^{\text {th }}, 5^{\text {th }}$, and $6^{\text {th }}$ grade was associated with more risky (i.e., smoking, drinking, fighting, and stealing items) behavior during the $6^{\text {th }}$ grade year. Students whose teachers rated relationships as closer were less likely to engage in risky student behaviors (Rudasill et al.) Positive relationships between students and teachers also promote feelings of bonding and connection to school. In research with students from $7^{\text {th }}$ to $12^{\text {th }}$ grade, school bonding and connectedness were related to decreased substance use (Catalano et al., 2004; Resnick et al, 1997), less violence and gang membership (Catalano et al., 2004), and delay in onset of sexual activity and less risk of suicidal behaviors (Resnick et al., 1997).

In addition to health related outcomes, high levels of emotional (i.e., perceptions of trust and communications of empathy) and instrumental (i.e., provision of time and skills) support from teachers are related to higher levels of subjective well-being for middle school students, as measured by life satisfaction and positive affect such as cheerfulness (Suldo et al., 2009). Adolescents in middle and high school with high teacher support also have higher scores on a self-concept scale that represents three domains: self-image, academic competence, and social competence (Demaray et al., 2009). Research demonstrates that teacher support is not only associated with a student's global view of the self, but is also connected to specific problem behaviors in middle and high school such as decreased suspensions and fewer incidents of cutting class (Brewster $\&$ Bowen, 2004; Crosnoe et al., 2004). Furthermore, early adolescents' (i.e., $6^{\text {th }}$ and $7^{\text {th }}$ 
graders) reports of school connectedness (feeling close to people at school and feeling a part of the school) predicted lower levels of conduct problems a year later. This finding is particularly important because it suggests that student-teacher relationships not only affect concurrent outcomes, but also have lasting effects on development. Finally, the relationship a student has with a teacher is associated with a decrease in depressive symptoms for adolescents during high school (Ellonen, Kaariainen, \& Autio, 2008; LaRusso et al., 2008) and middle school (Reddy, Rhodes \& Mulhall, 2003). The supportive relationship with the teacher may be associated with a decrease in depressive symptoms because students feel more respected and have an increased sense of belonging to the school (LaRusso et al. 2008).

Taken together, research documents the importance of the student-teacher relationship for student development. It appears that teacher support is not only linked to students' academic achievements, but also to the degree of healthy emotional, social, and behavioral functioning across environments. A high quality relationship with a teacher has even been shown to influence how peers perceive each other in the classroom. Given the importance of the relationship between a teacher and a student, it is necessary to understand the variables the influence the quality of the relationship.

\section{Contributors to Teacher-Student Relationship Quality}

Research findings make it apparent that teacher-student relationships are important for student success in academics and better social, emotional, and behavioral functioning. Based on the bioecological model of development (Bronfenbrenner \& Morris, 1998) the proximal processes between a student and teacher are influenced by characteristics of the student and the environment. Research has typically focused on 
demographic characteristics of the student such as gender (Baker, 2006; Birch \& Ladd, 1997; Pianta \& Stuhlman, 2004), socioeconomic status (Ladd et al., 1999; Pianta et. al, 2005), and internalizing and externalizing problems (Berry \& O'Connor, 2010; Meehan et al., 2003; Pianta \& Stuhlman, 2004) in predicting student-teacher relationship quality. Little attention has been paid to the home environment and the potential impact it has on the relationship between a student and teacher. This study expands upon previous research by examining the under-studied, but important, environmental variable of parental involvement in education. This study also includes behavioral characteristics, gender, and income in an effort to specifically examine the effects of these variables on the relationship between students and teachers during adolescence.

\section{Parental Involvement.}

Parental involvement in a student's education is an important element in the formula for a student's academic success. Parents may be involved in both the home and school environment. Home-based involvement typically includes tasks such as helping with homework, assisting in course selection, and talking about academic issues (Pomerantz et al., 2007). Home involvement may also include tasks that engage the child or adolescent in intellectual activities such as going to a museum or the library (Pomerantz et al.). School-based involvement is representative of those activities that involve actual contact with the school. These include being present for school meetings, attending school events, conversing with teachers, and volunteering at the school (Pomerantz et al.).

Epstein (2007) also identifies various ways that families and community partners can be involved in schools. Six types of involvement are identified. They are: (a) 
parenting- providing materials to help families understand developmental processes of children and adolescents; (b) communicating- creating two-way communication activities that keep families informed of school activities and student progress; (c) volunteeringactivities that recruit families and community partners to volunteer at school functions and activities; (d) learning at home- creating activities for students and families to complete at home that are coordinated with the school curriculum; (e) decision makingproviding opportunities for families to have an input in school decisions and policies; (f) collaborating with the community- identifying resources and services from the community that can assist schools, families, and students (Epstein, 2007; Sanders, Epstein, \& Connors-Tadros, 1999). Research has shown that when schools implement strategies to involve parents in these different spheres it can improve student attendance (Epstein \& Sheldon, 2002), as well as strengthen family involvement in health related topics by assigning homework to set health related goals for the family and having family input on food choices in the school (Michael, Dittus, \& Epstein, 2007).

In order to more fully understand the construct of parental involvement, it is important to know what factors influence parents to become involved in the academic lives of children and adolescents. Hoover-Dempsey et al. (2005) established a theoretical model to describe the multi-faceted precursors of parental involvement. This model includes three broad categories: parents' belief systems regarding parenting and efficacy; invitations from others to become involved; and elements of the parent's life context such as time and skills. Each category will be explored in more depth in the following paragraphs. 
A parent's belief system, as it relates to involvement in school, includes the role construction of being a parent and sense of efficacy for helping the child succeed (Hoover-Dempsey et al., 2005). Parental role construction focuses on a parent's beliefs about how to raise children and the role of a parent in education (Hoover-Dempsey et al.). For example, if a parent believes it is his/her responsibility to check in with an adolescent and make sure homework is completed or offer assistance when needed, then the parent is more likely to engage in home involvement activities such as homework assistance. In regards to a parent's sense of efficacy, parents who feel more effective in helping their children succeed will be more likely to engage in home involvement activities such as homework assistance (Watkins, 2001). Conversely, when parents feel they have a knowledge deficit related to their child's academics, they may be less likely to be involved (Pearl \& Bryant, 2000).

Invitations for a parent to be involved in the education process can originate from the school, the teacher, or the child (Hoover-Dempsey et al., 2005). In studies investigating predictors of parent involvement, the relationship between a parent and the teacher has emerged as a related factor (Carlisle, Stanley, \& Kemple, 2005; Kohl, Lengua \& McMahon, 2000; Knopf \& Swick, 2007; O’Connor, 2001). When parents and teachers perceive their relationship to each other as more positive, higher levels of parental involvement in both home and school occur (Nzinga-Johnson, Baker \& Aupperlee, 2009). In one case study at an urban elementary school, the degree of friendship between parent and teacher, as well as overall attitudes of teachers towards parents, was associated with whether or not a parent became involved in the school (O'Connor, 2001). A teacher's attitude (i.e., supportive or against) towards parental involvement can also 
significantly impact the actual level of involvement by the parent (Carlisle et al., 2005). In regards to invitations from the school, parents that feel welcome and rate school receptivity as high are more likely to be involved in the education of their child (Overstreet, Devine, Bevans \& Efreom, 2005). Invitations from a child take the form of asking for help with homework or to attend school events (Hoover-Dempsey et al., 2005). Parents of adolescents in grades 7-9 are more likely to be involved in homework and participate in school functions if asked by their child (Deslandes \& Bertrand, 2005). Given that adolescents seek more autonomy as they age, parent home involvement activities such as helping with homework change shape in that parents may decrease direct involvement and focus more on checking in and being supportive regarding autonomous functioning in relation to school (Cooper, Lindsay \& Nye, 2000). Finally, while parents may offer less direct support, evidence shows that adolescents in grades 6-8 can still benefit from parents helping them organize their work environment and modeling coping strategies to deal with stress when homework becomes more difficult (Xu \& Corno, 2003).

The extent to which parents are involved in the education of their children is also related to contextual factors in the parents' lives. These include socioeconomic status, culture, and skills/time (Hoover-Dempsey et al., 2005). More access to social capital (i.e. friend networks and having friends with children at the same school) is related to more home and school involvement (Sheldon, 2002), whereas lower socioeconomic status and less time availability are related to lower parental involvement. Parents with lower SES may have less flexibility in work hours for attending meetings (Hoover-Dempsey et al., 2005). In regards to time availability, one study showed that school-based parental 
involvement in Head Start was lower for those parents that were employed (Castro, Bryant, Peisner-Feinberg \& Skinner, 2004).

Research indicates that a family's cultural background has a significant impact on the extent and ways parents are involved in their children's education. Minority immigrant parents report feeling a greater number of barriers to involvement than their white counterparts, including not feeling welcome at the school, inconvenient meeting times, and transportation problems (Turney \& Kao, 2009). Transportation problems were also sited as barriers to African American parental involvement, as well as factors such as feeling intimidated by school personnel and parents' negative feelings about their own school experiences (Koonce \& Harper, Jr., 2005). Research shows that low-income African American parents' school experiences were often low quality, thereby hindering the development of knowledge and skills necessary to effectively navigate the school system (Diamond \& Gomez, 2004). Schools that have successfully worked with minority parents to increase involvement have established more flexible meeting times and locations, set higher expectations for minority students (Archer-Banks \& BeharHorenstein, 2008), hired translators to participate in meetings, and increased opportunities for informal communications (i.e., notes in the agenda) and presence at school (i.e., assist with field trips) (Ladky \& Peterson, 2008).

Regardless of how parents come to be involved in their children's education, parental involvement in both home and school based activities is linked to a student's academic performance and emotional reaction towards school (Barnard, 2004; Dearing, Kreider, Simpkins \& Weiss, 2006; Fantuzzo, McWayne, Perry \& Childs, 2004; Isakson \& Jarvis, 1999; Pomerantz et al., 2007). A comprehensive literature review examining 
parental involvement strategies in the home (e.g., parent tutoring, reading to the child), indicated that parental involvement is positively related to improvements in academic areas of reading and math among elementary students (Fishel \& Ramirez, 2005). In related literature, book reading in the home is related to a child's language skills in kindergarten, parent teaching of literacy is related to literacy skills in first grade, and exposure to storybooks is related to advanced levels of reading comprehension in fourth grade (Senechal, 2006). Research also indicates that parental involvement in school activities is strongly linked to reading and literacy achievement for students (Clements, Reynolds, \& Hickey, 2004; Dearing et al., 2006; Miedel \& Reynolds, 1999). As early as kindergarten, parental involvement is linked to an increase in a child's ability to analyze words. Furthermore, parental involvement also predicts later school outcomes such as reading achievement and high school completion (Clements, et al., 2004), particularly for economically disadvantaged youth (Dearing et al., 2006; Miedel \& Reynolds, 1999).

Higher levels of school-based parental involvement during elementary school are also predictive of academic variables such as decreased rates of high school dropout and higher rates of on-time school completion (Barnard, 2004). In addition, parental involvement in school activities for disadvantaged youth is linked to lower rates of grade retention by eighth grade as well as fewer years in special education classes (Miedel \& Reynolds, 2000). Overall, both home and school based parent involvement activities are related to higher levels of academic achievement from elementary to high school (Pomerantz et al., 2007).

In addition to academic achievement, parental involvement as early as preschool is related to a student's emotional commitment and reaction to school. Research has 
shown that home involvement is linked to higher levels of motivation and attention, and a more positive attitude toward learning for children in Head Start (Fantuzzo et al., 2004).

During early adolescence (i.e., $4^{\text {th }}-6^{\text {th }}$ grade), the relationship between students and family and parents' home involvement (i.e., organization and academic support) is related to higher reports of scholastic self-concept (i.e., feelings of self esteem and competence related to school work) (DuBois, Eitel, and Felner, 1994). An adolescent's perception of a parent's support and willingness to be involved in school activities at home continues to matter during the transition to high school (Isakson \& Jarvis, 1999). Adolescents who perceived parents as offering more academic support at home (i.e., offering help with a bad grade) reported a higher sense of school belonging (Isakson \& Jarvis).

Two extensive literature reviews provide evidence for the positive effect of parental involvement on emotional functioning in the school environment (GonzalezDehass, Willems \& Holbein, 2005; Pomerantz et al., 2007). Parental involvement is linked to higher levels of self-esteem, better emotion regulation skills, and decreased negative emotional functioning such as depression (Pomerantz et al.). Furthermore, parental involvement is connected to enhancement of social functioning, improved behavioral conduct, and better relationships with peers (Pomerantz et al.). A literature review by Gonzalez et al. (2005) indicated that more parent involvement from kindergarten to high school is related to several positive emotional outcomes for students, including higher perceived control and competence, self-efficacy, attention and concentration, and motivation to complete school tasks.

An emerging body of literature examines the association between the parent and teacher relationship and student achievement. Studies have shown the connections 
students feel with both teachers and parents work together to predict achievement growth in math (Gregory \& Weinsten, 2004). In addition, Gutman and Midgley (2000) found an additive effect of parental involvement and teacher support. When students had both high levels of parental involvement and teacher support they had higher GPAs than when either parental involvement or teacher support was examined alone.

While research suggests that students experience higher achievement when parents and teachers work together well, it is also important to examine how parental involvement influences the relationship a student has with his/her teacher. Few studies have examined this specific relationship. Mantzicopoulos (2005) found that children in kindergarten had higher levels of relational conflict with teachers when parent relationships within the school were less positive. Other research shows that increased levels of parental involvement are connected to improvements in the relationship between teacher and student (Dearing, Kreider \& Weiss, 2008; Wyrick \& Rudasill, 2009), and suggests that parental involvement matters most for decreasing student-teacher conflict for those students from low-income families (Wyrick \& Rudasill). One study has found that high school students who feel academic encouragement from parents also report higher levels of perceived teacher care (Chen \& Gregory, 2010). Collectively, research indicates that parental involvement is important for improved academic and attitudinal aspects of a student's education. Research also supports the need to further examine the relationship that exists between parental involvement and the student-teacher relationship. 


\section{Behavioral Characteristics.}

Behavioral characteristics are a type of student demographic that are often explored as predictors of student-teacher relationships. Measures of behavioral characteristics typically focus on two types of problems: internalizing and externalizing. Internalizing and externalizing problems reflect different patterns of emotional difficulties (Achenbach, 1991). Internalizing problems are characterized by psychological distress such as depression, anxiety, somatic complaints, and obsessions (Achenbach). Externalizing problems are characterized by more observable child behaviors such as aggression, hyperactivity, delinquency, and opposition (Achenbach). Both categories of behavioral characteristics have been shown to be associated with the quality of the relationship between student and teacher. For example, internalizing and externalizing problems are related to lower levels of closeness (Henricsson \& Rydell, 2004; Stuhlman \& Pianta, 2001) and higher levels of conflict (Jerome, Hamre \& Pianta, 2008; Pianta \& Stuhlman, 2004). In fact, research suggests that associations between the quality of teacher-student relationships and behavioral characteristics are reciprocal (Berry \& O'Connor, 2010; Hamre \& Pianta, 2005; Loukas, Ripperger-Suhler \& Horton, 2009; Pianta \& Stuhlman, 2004). That is, the quality of teacher-student relationships can be connected to a reduction or exacerbation of behavioral characteristics and, in turn, behavioral characteristics can influence the quality of teacher-student relationships. Furthermore, research has demonstrated that supportive teacher-student relationships can moderate the influence of negative peer interactions on development of emotional and behavioral problems. For example, adolescents that experienced relational victimization by peers (i.e., peers telling lies about the individual) and reported higher levels of support 
from a teacher were less likely to experience emotional and behavioral problems than students that had less supportive relationships with teachers (Yeung \& Leadbeater, 2010).

Internalizing Problems. Internalizing problems are most often characterized as problems that occur within the self and are identified as changes in mood or emotion (Graber \& Sontag, 2009). Examples include anxiety, withdrawal from social interactions, depression, and somatic complaints with no known medical cause (Achenbach, 1991). Approximately 5-6\% of adolescents exhibit high scores on the anxious/depressed syndrome scale of internalizing problems (Graber \& Sontag, 2009). The dysregulation of emotion experienced by adolescents with internalizing problems can be viewed as either an over-internalization of emotions such as anxiety or the over-identification with the emotions of others (i.e., inability to distinguish one's own emotional state from a significant other, such as a parent) (Graber \& Sontag, 2009). As internalizing problems typically peak during adolescence and young adulthood (Graber \& Sontag), the impact of such problems on relationships may be greater at this time.

Internalizing problems have been linked to student-teacher relationship quality. In addition, the quality of the teacher-student relationship may also mediate or moderate the association between internalizing problems and aspects of school success. For example, Baker (2006) found that when elementary school-aged children with high levels of internalizing problems had high quality relationships with a teacher, they received average or above average scores on academic achievement and classroom adjustment (i.e., following rules and getting along with peers). Furthermore, high quality relationships from kindergarten to sixth grade are associated with more positive social skills for those children who demonstrate low levels of internalizing problems (Berry \& 
O’Connor, 2010). Conversely, when first grade teachers rate students as having less close and more conflictual relationships, maternal reports of internalizing problems are higher (Pianta \& Stuhlman, 2004). Baker, Grant and Morlock (2008) found that when students with internalizing problems also rated high on a conflict scale with a teacher, they showed poorer school adaptation (i.e., work habits). Finally, research has supported that a positive interpersonal connection between teachers and students can be even more important for academic and emotional outcomes for those students affected by internalizing problems such as depression (Johnson, Eva, Johnson, \& Walker, 2011). Thus, a high quality relationship with a teacher may buffer negative academic and behavioral consequences for those students who embody internalizing problems, while a conflictual relationship may exacerbate student difficulties.

Students' internalizing problems have also been directly linked to the quality of student-teacher relationships. For example, higher levels of internalizing problems are related to student-teacher conflict in kindergarten, second, third, and fourth grade (Jerome et al., 2008). Work by Murray and Murray (2004) further supports the connection between internalizing problems and conflict for students in third through fifth grade. Internalizing problems have also been linked to decreased levels of closeness between teacher and student during second and third grade (Henricsson \& Rydell, 2004).

Research from studies examining shyness and student teacher relationship quality further support the connection between internalizing problems and student-teacher relationships. Although shyness is not synonymous with internalizing problems, it is an indicator. Children who are shy often have more anxiety related behaviors, especially in social situations (Biederman et al., 2001; Gladstone et al., 2005; Kennedy, Rapee \& 
Edwards, 2009). Rudasill, Rimm-Kaufman, Justice and Pence (2006) found that shyer preschool children with good language skills had more dependent relationships (i.e., overreliance, asks for help when not needed) with their teachers. Furthermore, teachers reported less closeness in relationships with shyer children in preschool (Justice, Cottone, Mashburn \& Rimm-Kaufman, 2008). Researchers hypothesize that the relationship is less close because shy children are less likely to initiate communication with the teacher, thereby hindering opportunities for connection (Justice et al.).

Externalizing Problems. Externalizing problems are characterized as a group of behaviors that involve overt acting out patterns such as delinquency and aggression (Achenbach, 1991). Delinquency most often involves some violation of the law such as violence, theft, vandalism, and drug use. The delinquency scale is closely related to a diagnosis of conduct disorder, which includes aggression toward people or animals, property destruction, violation of rules, and stealing or lying (Farrington, 2009). According to self-report measures, it is estimated that $20 \%$ of males at age 17 and $12 \%$ of females age 15-17 have committed an act of violence (Farrington). Aggression as an externalizing problem is defined as a behavior that is intended to and actually does harm to another either in a physical or verbal manner (Farrington). Another characteristic of externalizing problems is impulsive behavior such as not considering consequences before acting, low self-control, and difficulty in delay of gratification (Farrington).

Externalizing problems can serve as a unique predictor in the quality of the relationship between teacher and student. Similar to internalizing problems, the relationship between externalizing problems and the quality of the teacher-student relationship is reciprocal. Beginning in first grade, students who experience more conflict 
with teachers are also rated higher on externalizing problems (Pianta \& Stuhlman, 2004). In a detailed examination of the reciprocity between externalizing problems and teacher relationship quality, aggressive behavior at the start of kindergarten was related to increased conflict with the teacher in the middle of the year (Doumen et al., 2008). Subsequently, the teacher conflict led to more aggressive behaviors by the students at the end of the year (Doumen et al.).

Research suggests that student-teacher relationships may also be beneficial for children with aggressive behaviors. For example, Hamre and Pianta (2005) found that high quality relationships with first grade teachers, as measured by emotional warmth and support, helped children with externalizing behavioral difficulties achieve higher scores in academics. A more positive relationship with a teacher (i.e., provision of support) during second and third grade has also been linked to decreased levels of aggression (Meehan et al., 2003). An additional study documented that, for elementary children with high externalizing problems, closeness with a teacher was associated with a decrease in those problems over time (Silver, Measelle, Armstrong \& Essex, 2005). In similar studies examining middle school students, student ratings of school connectedness (i.e., feeling close to people at school) negatively predicted conduct problems such as fighting and cheating a year later (Loukas, Ripperger-Suhler \& Horton, 2009) and higher ratings of student-teacher relationship quality in $6^{\text {th }}$ grade have been linked to a lower probability of engaging in problem behaviors (i.e., truancy and theft) in $7^{\text {th }}$ and $8^{\text {th }}$ grades (Wang, Selman, Dishion, \& Stormshak, 2010). Furthermore, teachers' use of a relational approach to discipline (i.e., emphasis on personal connection with individual students) was connected to less defiant and more cooperative behavior from high school students, 
which was mediated by the level of trust the adolescent felt for the teacher (Gregory \& Ripsky, 2008) Overall, positive teacher-student relationships can moderate negative effects of externalizing problems, and negative teacher-student relationships can exacerbate the negative outcomes for children with externalizing problems.

In addition, externalizing problems also predict the quality of the teacher-student relationship. In a study examining kindergarten and first grade teachers' narratives regarding their relationships with students, teachers reported feeling more negative affect towards those students who displayed more negative behavior in the classroom (Stuhlman \& Pianta, 2001). Kindergarten children who have been labeled with antisocial styles of interacting (i.e., engaging in hostile and coercive acts) have lower ratings of closeness with teachers (Ladd et al., 1999).

Externalizing characteristics are most often related to the degree of conflict found in the relationship between a student and teacher. Murray and Murray (2004) found that for third, fourth, and fifth graders, higher ratings of externalizing problems were related to greater conflict with the teacher. In other studies examining kindergarten, second, third, and fourth grade, externalizing problems were significantly related to higher levels of conflict within the teacher-student relationship (Henricsson \& Rydell, 2004; Jerome et al., 2008). With regard to specific components of externalizing problems, children who display more anger in their behavioral interactions in a preschool classroom experience more conflict with teachers (Justice et. al, 2008). Furthermore, an indicator of externalizing problems is low effortful control. This reflects a child's ability to inhibit behavioral responses and concentrate on tasks (Rudasill \& Rimm-Kaufman, 2009). Children in first grade who were rated as lower on effortful control in preschool 
experienced more conflict with the teacher, whereas children rated as higher in effortful control experienced more closeness (Rudasill \& Rimm-Kaufman).

\section{Gender.}

The quality of the relationship between a teacher and a student is clearly linked to student gender (Baker, 2006; Birch \& Ladd, 1997; Kesner, 2000; O'Connor \& McCartney, 2006; Saft \& Pianta, 2001). Research on gender has focused on children during elementary school and the middle school transition. To date, little research has focused on gender as a factor in research examining adolescents' perceptions of teacher relationships.

Research has shown that girls have an overall higher quality of relationship with teachers (O’Connor \& McCartney, 2006; Pianta \& Stuhlman, 2004). More specifically, girls are rated as having higher degrees of closeness and lower levels of conflict with teachers (Baker, 2006; Birch \& Ladd, 1997). In turn, research has shown that high levels of closeness are also more beneficial for girls on measures of social competence. This means that for girls, not boys, higher levels of closeness in the relationship predicts school appropriate behaviors and better social behaviors such as being considerate of others (Ewing \& Taylor, 2009). The gap between males and females on closeness with teachers continues to grow throughout elementary school. Female students experience a smaller decline in the degree of closeness with a teacher than their male counterparts (Jerome et al., 2009). In other research using measures of teacher support (i.e., enjoyment of being with the child and perceived ability to nurture the child) rated by the teacher, girls experienced higher levels of support in first grade (Hughes, Gleason \& Zhang, 2005). In addition, when third and fourth graders rated their peers on level of support 
received by teachers, girls were still viewed as receiving more support than boys (Hughes et al., 2001). This higher level of teacher support is related to lower levels of school avoidance for girls (Murray, Waas \& Murray, 2008). In the one study examining gender and teacher relationships in high school, $12^{\text {th }}$ grade female students rated teachers higher on levels of genuineness than their male counterparts (Drevets, Benton \& Bradley, 1996). Furthermore, students perceived a greater positive regard from teachers if the teacherstudent dyad was the same gender (Drevets et al.).

Whereas girls experience more closeness in teacher relationships, teachers typically perceive relationships with boys to be less close and more conflictual (Kesner, 2000). Indeed, there is extensive support in the literature for the notion that teachers experience more conflict in relationship with boys (Baker, 2006; Birch \& Ladd, 1997; Hughes et al., 2001;Ladd et al., 1999; Murray et al., 2008; Saft \& Pianta, 2001), and this conflict seems to be particularly harmful for boys. The increase in the amount of conflict in teacher-student relationships for boys has been linked to a decrease in school competence, an increase in hostile aggressive behavior (Ewing \& Taylor, 2009), and lower grades (DiLalla, Marcus \& Wright-Phillips. 2004). The effects of high levels of conflict continue throughout elementary school. In a longitudinal study examining children in grades $\mathrm{K}-6$, boys who received higher ratings of conflict in previous grades were rated higher in conflict by each subsequent teacher (Jerome et al., 2009). Furthermore, kindergarten teachers' perceptions of conflict in boys are significantly related to academic outcomes throughout elementary and middle school (Hamre \& Pianta, 2001). 
Gender differences in teacher-student relationships have been explained by the differing characteristics of boys and girls upon entering school. When Baker (2006) found that girls benefit more from positive teacher-student relationships, she interpreted this as a result of girls being more attuned to social and relational variables. This attunement allows for girls to have teacher relationships that are "emotionally vested" (Baker, 2006, p. 225). The level of attunement between girls and teachers may also put girls in better position to reap benefits from the socialization efforts (i.e., appropriate classroom behaviors) from teachers (Ewing \& Taylor, 2009). Furthermore, given that the majority of teachers are female and females are more apt to be relationally focused, boys may have a harder time connecting to teachers than girls (Kesner, 2000). Research has indicated that boys may receive more attention in the classroom due to being more assertive, yet this attention can often take the form of negativity and redirection which can further harm the teacher-student relationship (Kesner). Lastly, boys have been socialized to display more aggressive and dominating actions whereas girls are typically socialized to be more quiet and obedient to others. These different gender socializations may help explain why boys typically experience more conflict with teachers whereas girls experience more closeness (Ewing \& Taylor, 2009).

\section{Income.}

Income is an environmental factor that has been linked to various childhood outcomes. The most notable relationship exists between income and academic achievement. For example, a child's poverty level has been linked to whether or not they experience a successful transition to kindergarten (Rimm-Kaufman \& Pianta, 2000). In a study of children three to five years, those from higher income homes had higher 
cognitive test scores than those children living in lower income homes (Yeung, Linver \& Brooks-Gunn, 2002). This link between cognition and income could be due to levels of parent stress, availability of intellectually stimulating items in the home, and availability of parents for assistance in education processes (Yeung et al.). A study by Votruba-Drzal (2003) offers support for this argument with results that family income is related to the level of cognitive stimulation that children receive in the home environment. When poverty exists at persistent levels during elementary school, a child's risk of school failure is significantly increased (De Civita, Pagani, Vitaro \& Tremblay, 2004).

Income is also linked to children's psychological health and behavioral outcomes such as self-regulation (Evans, Gonnella, Marcynyszyn, Gentile \& Salpekar, 2005). Findings from a comprehensive literature review examining family poverty showed children who live in poverty are more likely to be socially withdrawn, depressed, experience behavior and conduct problems, and have poorer peer relationships (Seccombe, 2000). Results from another study demonstrated that when children with higher levels of income display externalizing behaviors, the behaviors develop at a slower rate and are easier to decrease than when the behaviors are displayed by lowincome counterparts (Silver, Measelle, Armstrong \& Essex, 2005). While these studies demonstrate direct effects of income on social outcomes, other work suggests that income influences social and emotional competence through elements such as parental stress (Gershoff, Aber, Raver \& Lennon, 2007), parental psychological distress, and parental responsive and effective discipline (Mistry, Vanderwater, Huston \& McLoyd, 2002). Parents that are working more hours or experience more stress because of financial 
instability have less time and capacity to be supportive and sensitive to their child's social, emotional, cognitive, and behavioral development.

With regard to the relationship between teacher and student, the quality of the relationship is poorer in preschool classrooms where the majority $(60 \%)$ of children live below the poverty line (Pianta et al., 2005). Conversely, kindergarten children with socioeconomic advantages experience closer teacher-student relationships (Ladd et al., 1999). Levels of parent involvement can influence the impact of income on teacherstudent relationship quality. For example, low-income third grade children are rated as having less conflict with a teacher when parents are involved (Wyrick \& Rudasill, 2009). Furthermore, higher levels of family involvement in a low-income sample correspond to improvements in elementary children's ratings of the relationship with a teacher (Dearing et al., 2008).

Studies using maternal education as a proxy for socioeconomic status show similar findings. In a study of first grade children, maternal education was negatively correlated with children's emotional and behavioral problems (Hoglund \& Leadbeater, 2004). Level of maternal education has also been negatively correlated with academic outcomes for elementary aged children (Burchinal, Peisner-Feinberg, Pianta \& Howes, 2002; Hamre \& Pianta, 2005). Taken together, research indicates that the variable of income, no matter the definitional properties, is important in understanding relationships and school outcomes for students.

\section{Research Questions}

This study is designed to broaden the understanding of contributing factors to adolescents' perceptions of their relationships with teachers. The study will join together 
research in the areas of parental involvement, behavioral characteristics, teacher-student relationships, as well as income and gender. This study aims to do so by addressing the following research questions.

1) To what extent does student-rated parental involvement predict studentperceived quality of the relationship between teacher and student?

2) To what extent do parent rated child behavioral characteristics (i.e., internalizing and externalizing problems) predict student-perceived quality of the relationship between teacher and student?

3) To what extent do behavioral characteristics of the student moderate the relationship between parental involvement and the quality of the relationship between teacher and student?

4) To what extent does income moderate the relationship between parental involvement and the quality of the relationship between teacher and student? 


\section{CHAPTER 3}

\section{Method}

\section{Participants}

Participants were children and their parents from the NICHD Study of Early Child Care and Youth Development (SECCYD). Beginning in 1991, a diverse sample of mothers and children were recruited to participate in the study from hospitals near the following cities: Boston, MA; Charlottesville, VA; Irvin, CA; Little Rock, AK; Lawrence, KS; Madison, WI; Morgantown, NC; Philadelphia, PA; Pittsburgh, PA; and Seattle, WA. From a pool of 5,416 eligible participants, 1, 364 mothers and children were randomly selected to participate in the study. The selected participants matched the economic, educational, and ethnic diversity of the areas from which the recruitment took place. This study utilized Phase IV of the NICHD SECCYD, which was conducted when the participants were ages 14 and 15 years old. This study includes a sample of 820 adolescents and their parents. At age 15, the sample is comprised of 51\% male participants and $49 \%$ female. The ethnic breakdown of the sample is as follows: $84.6 \%$ White, 9.1\% Black/African American, 4.4\% Other, 1.6\% Asian/Pacific Islander, and .2\% American Indian/Eskimo/Aleut. With regard to levels of parental education, $31 \%$ of mothers and $27 \%$ of fathers have at least 2 years of college. Participants with missing data on key variables were deleted. Participants with missing data were from lower income families $(\mathrm{t}=-3.18, \mathrm{p}<.05)$ and had higher scores on externalizing problems $(t=3.97, p<.001)$ and internalizing problems $(t=2.39, p<.05)$. 


\section{Procedures}

Collection of data for use in this study occurred when adolescents were 15 years of age. Data were collected from adolescents via questionnaires in the lab and in the home and from parents in the home only. Adolescents in the study were distributed across ten states. Additional information on sample, selection, procedures, measures, and data collection can be found in the Manuals of Operation of the National Institutes of Child and Human Development Early Child Care Research Network, available at http://www.nichd.nih.gov/research/supported/seccyd/overview.cfm.

\section{Measures}

Teacher Relations Questionnaire. Student-teacher relationship quality was assessed by adolescents' report using the Teachers Relations Questionnaire. The Teacher Relations Questionnaire was adapted from the Some of My Favorite People battery that was part of a Network of Relationships Inventory given during Phase III of the NICHD study (Furman, 1996; Furman \& Buhrmester, 1985). The original format of Some of My Favorite People, given during sixth grade, contained items related to a child's relationship with both a teacher and mentor. The Teacher Relations Questionnaire is comprised of 16 items that measure an adolescent's perception of the quality of his or her relationship with one teacher in school (i.e., the teacher to whom the adolescent felt closest to that year). This form was not given to adolescents that were home schooled. Items cover such topics as social support (e.g., "How often do you turn to this teacher for support with personal problems?"), instrumental support (e.g., "How much does this person teach you how to do things that you don't know?"), affective bonds (e.g., "How much does this teacher really care about you?"), and shared activities (e.g., "How much free time do you 
spend with this teacher?"), yielding a composite score, "Student Teacher Relationship Quality" which is computed as the mean. Students respond to each item using a 5-point Likert scale ( $I=$ little or none and $5=$ the most $)$. Cronbach's alpha for the current sample was .93 .

What My School Is Like. Student-teacher relationship quality was also assessed by adolescents' report using the What My School Is Like Questionnaire. This questionnaire has 19 items that measure students' perceptions regarding school climate, teacher behaviors, and study habits. As with the Teacher Relations Questionnaire, this questionnaire was not completed by adolescents that were home schooled. What My School is Like has three items : "My teacher(s) treat me fairly"; "I care what my teacher(s) think of me", "I feel very close to at least one of my teachers", that yields a composite score "Connections with Teachers." Students responded on a 4-point Likert scale ( $1=$ not at all true and 4-very true). Cronbach's alpha for the current sample was .62 .

Parental Involvement in Schooling. Parental involvement was assessed by adolescents using the Parental Involvement in School questionnaire (Steinberg, Brown, \& Dornbusch, 1996). The 5-item questionnaire (divided into section A for mother and section $\mathrm{B}$ for father) measures the degree to which both mother and father engage in various school-related activities. The questionnaire instructs adolescents to check NA (not applicable) if they do not have a mother or father. The questionnaire covers facets of parental involvement such as helping with homework, going to school programs, and assisting in the choice of classes. Adolescents responded on a 4-point Likert scale $(0=$ never and $3=N / A)$. Responses of $3=$ "NA" were re-coded to missing data before 
composite scores were created. The questionnaire yields composite mean scores for maternal involvement, paternal involvement, and parental involvement (i.e., average of both mother and father's involvement scores). For the purpose of this study, scores for both maternal involvement and paternal involvement will be used in separate analyses. Cronbach alphas for this sample are as follows: maternal involvement $(\alpha=.70)$ and paternal involvement $(\alpha=.84)$.

Child Behavior Checklist. The extent to which an adolescent has internalizing and externalizing problems was measured by mothers and fathers using the Child Behavior Checklist (Achenbach, 1991). The Child Behavior Checklist (CBCL) is a widely used measure for assessing social competence and problem behavior between the ages of 4 and 18. Parents are presented with a variety of behaviors and they rate how true each behavior is for their children on a 3-point scale $(0=$ not true of the child and $2=v e r y$ true of the child). According to instrument documentation provided by the NICHD SECCYD, items related to sports and non-sports activities; jobs and chores; involvement in organizations; interactions with siblings, peers, and parents; friendship; and academic performance were not included on the version of the CBCL administered to parents in this study. Remaining items were combined into standardized T-scores for total scales of Internalizing and Externalizing problems. Internalizing Problems is comprised of 30 items and is based on three syndrome scales: Withdrawn (e.g. "Would rather be alone than with others"), Somatic Complaints (e.g., "Physical problems without known medical cause"), and Anxious/Depressed (e.g., "Too fearful or anxious"). Cronbach's alpha for the Internalizing Problems Scale for the current sample is .83. Externalizing Problems is comprised of 27 items is based on the Rule Breaking (e.g., "Truancy, skips school") and 
Aggressive (e.g., "Physically attacks people") Scales (Achenbach, 1991). Cronbach's alpha for the Externalizing Problems Scale for the current sample is .89. For the purpose of this study, maternal ratings of Externalizing and Internalizing Problems were used due to the high number of participants missing paternal ratings.

Family Education and Income. Family income was measured by the Family Education and Income Questionnaire (Weinraub, 1996). This questionnaire contains 14 items that focus on aspects of family income, including education status of the parents, non-employment aid, and total family income. Mothers of the household completed the questionnaire when adolescents were 15 years old. For the purpose of this study, the question regarding pre-tax total family income will be used to document the adolescents' family income. Mothers were instructed to circle one of 27 options for income ranging from 1 (less than 5,000 ) to 27 (more than $\$ 1,000,000$ ).

\section{Data Analyses}

To determine the relationship between Parental Involvement and students' perceptions of relationship quality with a teacher, four regression analyses were conducted. The first two analyses regressed Maternal and Paternal Involvement scores on Student-Teacher Relationship Quality. The third and fourth analyses regressed Maternal and Paternal Involvement scores on Connections with Teachers. For each analysis, variables of Gender and Income were controlled in the first block. Similarly, the relationship between Internalizing and Externalizing Problems and students' perceptions of the quality of teacher relationships was analyzed using four regression analyses. The first two analyses regressed Internalizing and Externalizing Problems on Student-Teacher Relationship Quality, while the second analysis regressed Internalizing and Externalizing 
Problems on Connections with Teachers. Gender and Income were also controlled for in each analysis.

Additional regression analyses were run to determine the contributions of Internalizing Problems, Externalizing Problems, and Income beyond the association between Maternal and Paternal Involvement and Student Teacher Relationship Quality and Connections with Teachers. To investigate moderating effects of behavioral characteristics, models for Internalizing and Externalizing Problems were examined for each dependent variable (Student Teacher Relationship Quality and Connections with Teacher). In all models Gender and Income were entered into block one. For the remaining models, Block 2 consisted of either Maternal or Paternal Involvement, Block 3 consisted of either Internalizing or Externalizing Problems, and Block 4 contained one of the following interaction terms: Maternal Involvement and Internalizing; Maternal Involvement and Externalizing; Paternal Involvement and Internalizing; and Paternal Involvement and Externalizing. To investigate the moderating effects of Income, similar analyses were conducted with both dependent variables of teacher relationship quality. Interaction terms for Income and both Maternal and Paternal Involvement were examined. 


\section{CHAPTER 4}

\section{Results}

\section{Descriptive Analyses}

Descriptive analyses of all variables were conducted. Average ratings for student report of Connections with Teachers was $(\mathrm{M}=3.18, \mathrm{SD}=.68)$ and Student Teacher Relationship Quality was $(\mathrm{M}=2.43, \mathrm{SD}=.72)$. The average student report of Maternal Involvement $(\mathrm{M}=1.48, \mathrm{SD}=.42)$ was slightly higher than ratings of Paternal Involvement $(\mathrm{M}=1.28, \mathrm{SD}=.48)$. The average Income for this group was $\$ 108,957(\mathrm{SD}=\$ 114,749)$, while the median Income is $\$ 85,000$. All means and standard deviations are displayed in Table 1. Students in the sample had below average scores on both Externalizing $(\mathrm{M}=44.94, \mathrm{SD}=10.27)$ and Internalizing $(\mathrm{M}=46.32, \mathrm{SD}=9.8)$ Problem scales. Results indicate that students in the sample felt high levels of bonding to all teachers, felt they received support from parents at least sometimes, and had low maternal ratings on internalizing and externalizing problems.

Correlational analyses revealed the most variables had relatively low intercorrelations (i.e., less than .3). Exceptions were measures of Parental Involvement, Externalizing and Internalizing Problems, Student-Teacher Relationship Quality and Connections with Teachers. Measures of Maternal and Paternal Involvement were highly correlated $(r=.58)$, meaning that students reporting higher Maternal Involvement were also likely to report higher Paternal Involvement. Maternal ratings of Externalizing and Internalizing Problems were highly correlated $(r=.59)$. This indicates that students in this 
sample that rated high on Internalizing Problems were also displaying higher rates of Externalizing Problems. Lastly, student ratings of Student Teacher Relationship Quality and Connections with Teachers were moderately correlated $(r=42)$. Thus students who perceived a higher level of support from one teacher were likely to also report a higher level of support from teachers in general. Further examination of the correlation matrix revealed small, yet significant correlations among the variables. Students with higher levels of Maternal and Paternal Involvement reported higher levels of Student Teacher Relationship Quality and Connections with Teachers and had lower ratings of Internalizing and Externalizing Problems. Female students also indicated higher levels of Student Teacher Relationship Quality and Connections with Teachers. Table 2 shows the correlation matrix.

\section{Parent Involvement and Student-Teacher Relationships}

Question 1: To what extent does student-rated parental involvement predict student-perceived quality of the relationship between teacher and student?

To determine the extent to which Maternal and Paternal Involvement predicts the relationship between students and teachers beyond the effects of Income and Gender, a series of hierarchical regression analyses were conducted. Dependent variables for the analyses included Student Teacher Relationship Quality and Connections with Teachers. Results are shown in Table 3 (Student Teacher Relationship Quality) and Table 4 (Connections with Teachers).

Maternal Involvement and Student Teacher Relationship Quality. For step 1, Gender and Income significantly predicted Student Teacher Relationship Quality $\left(F_{2,819}\right.$ $=2.46, p<.01, R^{2=} .012$ ). Girls and students with lower family incomes were more likely 
to report higher levels of Student Teacher Relationship Quality. Together, these variables explained $1.2 \%$ of the variance in Student Teacher Relationship Quality. With the addition of Maternal Involvement in Step 2, the model remained significant $\left(F_{3,89 l}=16.80, p<.001{ }^{\wedge} R^{2=} .046\right)$. Results indicated that Maternal Involvement was a significant predictor of Student Teacher Relationship Quality beyond Gender and Income $(\beta=.217, p<.001)$. Maternal involvement explained an additional $4.6 \%$ of the variance in Student Teacher Relationship Quality.

Paternal Involvement and Student Teacher Relationship Quality. Gender and Income significantly predicted Student Teacher Relationship Quality $\left(\mathrm{F}_{2,819}=4.84, \mathrm{p}<.01\right.$, $R^{2=} .012$ ), with girls and students with lower incomes more likely to perceive higher levels of teacher support. These variables accounted for $1.2 \%$ of the variance in Student Teacher Relationship Quality. In step 2, Paternal Involvement was added to the model, and the model remained significant $\left(\mathrm{F}_{3,819}=10.37, \mathrm{p}<.001,{ }^{\Delta} R^{2=} .025\right)$. This was an indication that Paternal Involvement was a significant predictor $(\beta=.160, p<.001)$ and accounted for an additional $2.5 \%$ of the variance.

Maternal Involvement and Connection with Teachers. For step 1, Gender and Income significantly predicted Connection with Teachers $\left(F_{2,819}=7.98, p<.001, R^{2=} .019\right)$. Girls and students with higher family incomes were more likely to be perceive higher levels of teacher support. Together, these variables explained $1.9 \%$ of the variance in Connection with Teachers. With the addition of Maternal Involvement in Step 2, the model remained significant $\left(F_{3,819}=51.35, p<.001,{ }^{\wedge} R^{2=} .140\right)$. Results indicated that Maternal Involvement was a significant predictor of Connection with Teachers beyond 
Gender and Income $(\beta=.376, p<.001)$. Maternal Involvement predicted an additional $14 \%$ of the variance in Connection with Teachers.

Paternal Involvement and Connection with Teachers. Gender and Income were significant predictors of Connection with Teachers $\left(F_{2,819}=7.98, p<.001, R^{2=} .019\right)$, with girls and students with higher incomes indicating higher levels of bonding with teachers. Together, these student and family variables explained $1.9 \%$ of the variance in Connection with Teachers. In step 2, the model remained significant with the addition of Paternal Involvement $\left(\mathrm{F}_{3,819}=35.60, \mathrm{p}<.001,{ }^{\Delta} R^{2=} .097\right)$. This indicated that Paternal Involvement is a significant predictor of Connection with Teachers $(\beta=.315, \mathrm{p}<.001)$, and explained an additional $9.7 \%$ of the variance.

\section{Behavioral Characteristics and Student-Teacher Relationships}

Question 2: To what extent does parent rated child behavioral characteristics (i.e., internalizing and externalizing behaviors) predict student-perceived quality of the relationship between teacher and student?

The extent to which Internalizing and Externalizing Problems predict Student Teacher Relationship Quality and Connection with Teachers was examined by conducting a series of hierarchical linear regression analyses. Separate analyses examined each independent variable (Internalizing and Externalizing Problems) on the dependent variables of Student Teacher Relationship Quality and Connection with Teachers. Results are shown in Table 5 for Student Teacher Relationship Quality and Table 6 for Connection with Teachers.

Internalizing Problems and Student Teacher Relationship Quality. In model 1, Gender and Income were significant predictors of Student Teacher Relationship Quality 
$\left(\mathrm{F}_{2,819}=4.84, \mathrm{p}<.01, R^{2}=.012\right)$. Girls and students with lower family incomes experienced higher levels of Student Teacher Relationship Quality. These variables together predicted $1.2 \%$ of the variance in the student rating of Student Teacher Relationship Quality. With the addition of Internalizing Problems, the model did not remain significant $\left(\mathrm{F}_{3,819}=3.47\right.$, $\left.\mathrm{p}=.393,{ }^{\Delta} R^{2}=.001\right)$. The Internalizing Problems score is not a significant predictor of student rated Student Teacher Relationship Quality.

Externalizing Problems and Student Teacher Relationship Quality. Model 1 indicated that Gender and Income were significant predictors of Student Teacher Relationship Quality $\left(\mathrm{F}_{2,819}=4.84, \mathrm{p}<.01, R^{2}=.012\right)$. Students with lower incomes and females perceived more teacher support. The model did not remain significant with the addition of Externalizing Problems $\left(\mathrm{F}_{3,819}=3.70, \mathrm{p}=.233,{ }^{\wedge} R^{2}=.002\right)$, indicating that the Externalizing Problems score is not a significant predictor of Student Teacher Relationship Quality.

Internalizing Problems and Connection with Teachers. In the first model, Gender and Income significantly predicted higher levels of Connection with Teachers $\left(\mathrm{F}_{2,819}=7.98, \mathrm{p}<.001, R^{2}=.019\right)$. Taken together, the variables predicted $1.9 \%$ of the variance in Connection with Teachers. In model 2, Internalizing Problems did not significantly predict levels of Connection with Teachers $\left(\mathrm{F}_{3,819}=5.32, \mathrm{p}=.911,{ }^{\Delta} R^{2}=.000\right)$.

Externalizing Problems and Connection with Teachers. The first model indicated that Gender and Income were significant predictors of Connection with Teachers $\left(\mathrm{F}_{2,819}=7.98, \mathrm{p}<.001, R^{2}=.019\right)$. In model 2 , the addition of Externalizing Problems did not significantly predict Connection with Teachers $\left(\mathrm{F}_{3,819}=6.56, \mathrm{p}=.055\right.$, $\left.{ }^{\triangle} R^{2}=.004\right)$. 


\section{Behavioral Characteristics, Parental Involvement, and Student-Teacher Relationships}

Question 3: To what extent do behavioral characteristics of the student moderate the relationship between parental involvement and the quality of the relationship between teacher and student?

The extent to which Internalizing and Externalizing Problems moderate the effect of either Maternal Involvement or Paternal Involvement on Student Teacher Relationship Quality and Connection with Teachers, a series of hierarchical linear regression analyses were conducted. Separate analyzes examined the impact of each interaction (Maternal Involvement x Externalizing Problems, Maternal Involvement x Internalizing Problems, Paternal Involvement x Externalizing Problems, and Paternal Involvement x Internalizing Problems) on the two dependent variables of Student Teacher Relationship Quality and Connection with Teachers. Results are shown in Table 7 for Student Teacher Relationship Quality and Maternal Involvement, Table 8 for Student Teacher Relationship Quality and Paternal Involvement, Table 9 for Connection with Teachers and Maternal Involvement, and Table 10 for Connection with Teachers and Paternal Involvement.

\section{Internalizing Problems, Maternal Involvement, and Student Teacher}

Relationship Quality. The first model indicated that Gender and Income are significant predictors of Student Teacher Relationship Quality $\left(\mathrm{F}_{2,819}=4.84, \mathrm{p}<.01\right.$, $\left.R^{2}=.012\right)$. The second model showed that with the addition of Maternal Involvement and Internalizing Behavior the model remained significant $\left(\mathrm{F}_{3,819}=13.04, \mathrm{p}<.001,{ }^{\wedge} R^{2}=.048\right)$, with the additional variance explained only by Maternal Involvement $(\beta=.220 p<.001)$. 
Finally, in the third model the interaction between Maternal Involvement and Internalizing Problems was not a significant predictor of Student Teacher Relationship Quality $\left(\mathrm{F}_{5,819}=10.49, \mathrm{p}=.555,{ }^{\triangle} R^{2}=.000\right)$. This indicates that Internalizing Problems did not moderate the impact of Maternal Involvement on Student Teacher Relationship Quality.

Externalizing Problems, Maternal Involvement, and Student Teacher

Relationship Quality. The first model indicated that Gender and Income are significant predictors of Student Teacher Relationship Quality $\left(F_{2,819}=4.84, p<.01\right.$, $R^{2}=.012$ ). With the addition of Maternal Involvement and Externalizing Problems, the second model maintained significance $\left(\mathrm{F}_{3,819}=13.61, \mathrm{p}<.001,{ }^{\wedge} R^{2}=.051\right)$ with only Maternal Involvement explaining the additional variance $(\beta=.225, \mathrm{p}<.001)$. The interaction term between Maternal Involvement and Externalizing Problems was entered into the third model and was not significant $\left(\mathrm{F}_{5,819}=10.93, \mathrm{p}=.621,{ }^{\triangle} R^{2}=.000\right)$. This indicates that Externalizing Problems does not moderate the impact of Maternal Involvement on Student Teacher Relationship Quality.

\section{Internalizing Problems, Paternal Involvement, and Student Teacher}

Relationship Quality. The first model indicated that Gender and Income are significant predictors of Student Teacher Relationship Quality $\left(\mathrm{F}_{2,819}=4.84, \mathrm{p}<.01\right.$, $R^{2}=.012$ ). Paternal Involvement and Internalizing Problems were added in the second model and the model remained significant $\left(\mathrm{F}_{3,819}=8.17, \mathrm{p}<.001,{ }^{\wedge} R^{2}=.027\right)$, with the additional variance only being explained by Parental Involvement $(\beta=.164, p<.001)$. The interaction term between Paternal Involvement and Internalizing Problems was added to the third model and the model was not significant $\left(\mathrm{F}_{5,819}=6.53, \mathrm{p}=.899,{ }^{\wedge} R^{2=} .000\right)$. This 
indicates that Internalizing Problems did not moderate the relationship between Paternal Involvement and Student Teacher Relationship Quality.

Externalizing Problems, Paternal Involvement, and Student Teacher

Relationship Quality. The first model indicated that Gender and Income are significant predictors of Student Teacher Relationship Quality $\left(\mathrm{F}_{2,819}=4.84, \mathrm{p}<.01\right.$, $R^{2-} .012$ ). The addition of Paternal Involvement and Externalizing Problems in the second model were also significant $\left(\mathrm{F}_{3,819}=8.69, \mathrm{p}<.001,{ }^{\wedge} R^{2}=.029\right)$, with the additional variance only explained by Paternal Involvement $(\beta=.170, p<.001)$. With the final addition of the interaction between Paternal Involvement and Externalizing Problems, the model was not significant $\left(\mathrm{F}_{5,819}=7.01, \mathrm{p}=.579,{ }^{\wedge} R^{2}=.000\right)$. This indicates that Externalizing Problems did not moderate the relationship between Paternal Involvement and Student Teacher Relationship Quality.

Internalizing Problems, Maternal Involvement, and Connection with Teachers.

Gender and Income in the first model significantly predicted

Connection with Teachers $\left(\mathrm{F}_{2,819}=7.98 \mathrm{p}<.001, R^{2}=.019\right)$. With the addition of Maternal Involvement and Internalizing Problems in the second model, the model remained significant $\left(\mathrm{F}_{3,819}=38.60, \mathrm{p}<.001,{ }^{\Delta} R^{2}=.140\right)$, with additional variance only explained by Maternal Involvement $(\beta=.378, p<.001)$. The interaction term between Maternal Involvement and Internalizing Problems was added to the third model and was not significant $\left(\mathrm{F}_{5,819}=31.45, \mathrm{p}=.110,{ }^{\Delta} R^{2}=.003\right)$. This indicated that Internalizing Problems did not moderate the impact of Maternal Involvement on Connection with Teachers.

Externalizing Problems, Maternal Involvement, and Connection with Teachers. In the first model including Gender and Income were significant 
predictors of Connection with Teachers $\left(\mathrm{F}_{2,819}=7.98, \mathrm{p}<.001, R^{2}=.019\right)$. The addition of Maternal Involvement and Externalizing Problems in the second model allowed the model to remain significant $\left(\mathrm{F}_{3,819}=38.62, \mathrm{p}<.001,{ }^{\wedge} R^{2}=.140\right)$, with additional variance only explained by Maternal Involvement $(\beta=.374, \mathrm{p}<.001)$. The interaction term between Maternal Involvement and Externalizing Problems was entered into the third model and was not significant $\left(\mathrm{F}_{5,819}=31.09, \mathrm{p}=.330,{ }^{\triangle} R^{2}=.003\right)$.

Internalizing Problems, Paternal Involvement, and Connection with Teachers. In model one, Gender and Income were significant predictors of Teacher Bonding $\left(\mathrm{F}_{2,819}=7.98, \mathrm{p}<.001, R^{2}=.019\right)$. The addition of Paternal Involvement and Internalizing Problems in model two allowed the model to remain significant $\left(\mathrm{F}_{3,819}=26.79, \mathrm{p}<.001,{ }^{\wedge} R^{2}=.091\right)$ with additional variance only explained by Paternal Involvement $(\beta=.316, p<.001)$. The interaction between Internalizing Problems and Paternal Involvement was entered in model three and was not found to be significant $\left(\mathrm{F}_{5,819}=21.52, \mathrm{p}=.470,{ }^{\triangle} R^{2}=.001\right)$. This indicates that Internalizing Problems did not moderate the relationship between Paternal Involvement and Connection with Teachers.

Externalizing Problems, Paternal Involvement, and Connection with Teachers.

Gender and Income were entered into model one and were significant predictors of Connection with Teachers $\left(\mathrm{F}_{2,819}=7.98, \mathrm{p}<.001, R^{2}=.019\right)$. Paternal Involvement and Externalizing Problems were added in model two and were a significant predictor of Connection with Teachers $\left(\mathrm{F}_{3,819}=26.79, \mathrm{p}<.001,{ }^{\Delta} R^{2}=.097\right)$ with additional variance only explained by Paternal Involvement $(\beta=.311, p<.001)$. In the third model, the interaction between Externalizing Problems and Paternal Involvement was added and the model was not significant $\left(\mathrm{F}_{5,819}=21.53, \mathrm{p}=.460,{ }^{\triangle} R^{2}=.001\right)$. This indicates 
that Externalizing Problems did not moderate the connection between Paternal Involvement and Connection with Teachers.

Income, Parental Involvement, and Student Teacher Relationships

Question 4: To what extent does income moderate the relationship between parental involvement and the quality of the relationship between teacher and student?

The extent to which Income moderates the association between Maternal Involvement or Paternal Involvement and Student Teacher Relationship Quality and Connection with Teachers was examined by conducting a series of hierarchical linear regression analyses. Separate analyzes examined the impact of each interaction (Maternal Involvement $x$ Income and Paternal Involvement $x$ Income) on the two dependent variables of Student Teacher Relationship Quality and Connection with Teachers. Results are shown in Table 11 for Student Teacher Relationship Quality and Table 12 for Connection with Teachers.

Income, Maternal Involvement, and Student Teacher Relationship Quality. In the first model, Gender and Income were significant predictors of Student Teacher Relationship Quality $\left(\mathrm{F}_{2,819}=4.24 \mathrm{p}<.01, R^{2}=.012\right)$. Maternal Involvement was added in the second model and maintained significance $\left(\mathrm{F}_{3,819}=16.8, \mathrm{p}<.001,{ }^{\Delta} R^{2}=.046\right)$. The addition of the interaction term between Maternal Involvement and Income was entered into model 3 and the model did not remain significant $\left(\mathrm{F}_{4,819}=13.44, \mathrm{p}=.072,{ }^{\Delta} R^{2}=.004\right)$. This indicates that income did not moderate the effects of Maternal Involvement on Student Teacher Relationship Quality. 
Income, Paternal Involvement, and Student Teacher Relationship Quality.

Gender and Income were entered in the first model and were significant predictors of Student Teacher Relationship Quality $\left(\mathrm{F}_{2,819}=4.84, \mathrm{p}<.01, R^{2}=.012\right)$. Paternal Involvement was added in the second model and was significant $\left(\mathrm{F}_{3,819}=10.37, \mathrm{p}<.001,{ }^{\wedge}\right.$ $R^{2}=.025$ ). With the addition of the interaction term between Paternal Involvement and Income, the third model did not remain significant $\left(\mathrm{F}_{4,819}=8.49, \mathrm{p}=.110,{ }^{\Delta} R^{2}=.003\right)$.

Income, Maternal Involvement, and Connection with Teachers. The first model included Gender and Income and was a significant predictor of Connection with Teachers $\left(\mathrm{F}_{2,819}=7.98, \mathrm{p}<.001, R^{2}=.019\right)$. The second model included Maternal Involvement and remained significant $\left(\mathrm{F}_{3,819}=51.35, \mathrm{p}<.001,{ }^{\Delta} R^{2}=.140\right)$. The third model included an interaction between Maternal Involvement and Income and did not remain significant $\left(\mathrm{F}_{4,819}=14.98, \mathrm{p}=.420,{ }^{\wedge} R^{2}=.001\right)$. This indicates that Income did not moderate the effects of Maternal Involvement on Connection with Teachers.

Income, Paternal Involvement, and Connection with Teachers. Gender and Income were included in the first model and were significant predictors of Connection with Teachers $\left(\mathrm{F}_{2,819}=7.98, \mathrm{p}<.001, R^{2}=.019\right)$. Paternal Involvement was added in the second model and was significant $\left(\mathrm{F}_{3,819}=35.60, \mathrm{p}<.001,{ }^{\Delta} R^{2}=.097\right)$. An interaction term between Paternal Involvement and Income was included in model three and the model was not significant $\left(\mathrm{F}_{4,819}=26.67, \mathrm{p}=.918,{ }^{\wedge} R^{2}=.000\right)$. This indicated that Income did not moderate the impact of Paternal Involvement on Connection with Teachers. 


\section{CHAPTER 5}

\section{Discussion}

Some of the hypotheses proposed in this research study were confirmed while others were not supported. The findings were congruent with my hypothesis of gender as a main effect, indicating that girls reported higher levels of teacher support. With regard to income, students from higher income households reported higher levels of teacher support when reporting on all teachers (Connections with Teachers). However, when asked to rate teacher support from one specific teacher (Student Teacher Relationship Quality), students from lower income households reported higher levels of teacher support. My hypothesis that higher ratings of internalizing and externalizing problems would be associated with lower ratings of teacher support was not supported. Parental ratings of the adolescent's internalizing and externalizing problems were not significantly related to either form of teacher support. As expected, higher levels of maternal and paternal involvement were connected to higher perceptions of teacher support from both a specific teacher (Student Teacher Relationship Quality) and all teachers in the school (Connections with Teachers). However, both maternal and paternal involvement explained greater proportions of the variance in perceptions of support from all teachers in the school than in perceptions of support from a specific teacher. 
In regards to my last hypothesis, internalizing and externalizing problems did not moderate the relationship between parental involvement and either forms of teacher support. Finally, income failed to moderate the relationship between parental involvement and either form of teacher support. Even so, results from this study offer further support for and understanding of the important role an adolescent's biological characteristics, environmental characteristics (family income), and proximal processes between microsystems (i.e., home and school) play in healthy development (Bronfenbrenner \& Morris, 1998).

\section{Gender}

Findings from this study indicate that gender is an important factor when considering adolescents' perceptions of support from teachers. The fact that gender emerged as a predictor of both forms of students' reports of teacher support provides support for my hypothesis and is congruent with previous literature for elementary students (Baker, 2006; Kesner, 2000; Saft \& Pianta, 2001). More specifically, results support literature indicating girls have an overall higher quality of relationship with teachers (O’Connor \& McCartney, 2006; Pianta \& Stuhlman, 2004). In this study, girls were more likely to report higher levels of support with both a specific teacher and teachers in general. These findings support previous research that $12^{\text {th }}$ grade female students find teachers to be more genuine than do male students (Drevets, Benton, \& Bradley, 1996). In addition, it is consistent with the finding that middle school females perceive more emotional support from their teachers (Wentzel, Battle, Russell, \& Looney, 2010). Given that females in this study experienced higher levels of teacher support, it can be inferred that they continue to reap the benefits of a close student- 
teacher relationship such as displaying appropriate classroom behaviors and having better social skills (i.e., being considerate of others) (Taylor \& Ewing, 2009).

\section{Income}

The mixed results of the relationship between income and teacher support warrants further discussion. As predicted, income was positively associated with teacher support when adolescents were asked to rate teachers in the school as a whole (Connections With Teachers). This finding supports previous research linking students' socioeconomic advantages to closer teacher-student relationships (Ladd et al., 1999). An adolescent's household income may also impact teacher support indirectly by influencing known teacher support predictors, such as variability in students' cognitive abilities (Yeung, Linver, Brooks-Gunn, 2002), amounts of parental stress and availability for school assistance (Mistry et al., 2002), and ability to regulate emotions and conduct in the school environment (Evans et al., 2005).

Furthermore, questions about teacher support for all teachers was assessed with an instrument measuring not only teacher behaviors, but also school climate and study habits. Research indicates adolescents from lower socioeconomic backgrounds find it more difficult to engage in the educational system, and more specifically, have less positive concrete attitudes (attitudes that reflect the reality about the payoff of education) regarding education (McLoyd et al., 2009). Youth from higher socioeconomic status households do not experience a decrease in educational aspirations during high school like their counterparts from lower income brackets (McLoyd et al.) The link between socioeconomic status and more positive attitudes and perceptions regarding education 
may help explain why adolescents in this sample with higher incomes also perceived more support when rating all teachers.

In contrast to my hypothesis, income was negatively related to students' reports of support from one specific teacher (Student Teacher Relationship Quality). Results indicated that as household income decreased, perceptions of support from one specific teacher increased. This result was surprising given that research points to better teacherstudent relationships for students from higher income families (Ladd et al., 1999; Pianta et al., 2005). One possible explanation for this unexpected finding in the current study is the fact that the average income for this sample is $\$ 108,957$ and the median income is $\$ 85,000$, while according the U.S. Census Bureau the median family income in 2006 was $\$ 48,451$. In addition, according to national statistics the maximum income allowed by poverty guidelines in 2006 (when the adolescents reported data) for a family of four was $\$ 20,000$ (http://aspe.hhs.gov/poverty/06poverty.shtml). Only $8.8 \%$ of the current sample had income reported at or below this level. Taken together, this indicates the majority of the current sample has higher incomes than the average American population. This could explain how results for this sample are different from other studies that have used data from children at or below the poverty level (Pianta et al., 2005). Most adolescents from "lower" income families in this sample were still living substantially above poverty levels, indicating that the results should be interpreted with caution regarding low-income statistics. Furthermore, data analyses indicated that income was statistically lower for those students with missing data, who were subsequently removed from this data set. This statistical process further truncated the poorer end of this sample, making it more 
difficult to capture the full range of income in the sample, inflating the mean and median, and creating a scenario where "low income" actually becomes middle-class.

In addition to the demographic distribution of this particular sample, an aspect of attachment theory offers a perspective as to why lower income adolescents might rate relationships with a particular teacher as more supportive than adolescents from higher income families. Research has documented that children living in low income households experience higher levels of emotional problems, lower academic functioning, and lower levels of physical health, which are mediated by high levels of parental stress and a lack of social support (Seccomobe, 2000). The lack of social support for low-income adolescents can be attributed to parental responses to attempts for autonomy (McElhaney et al., 2009). Autonomy is important for attachment development during adolescence. Adolescents begin to seek out more support from peers and engage in new experiences as they search for their own identity (McElhaney et al.). Parents are more likely to inhibit expressions of autonomy when these activities pose risk to an adolescent's well being, such as those stemming from an unhealthy or unsafe neighborhood environment (McElhaney et al.) Taken together, it seems that adolescents from low income homes may have less social support from chosen peer groups in their environment, thereby turning more to teachers for social support and caring. In addition, adolescents coming from home environments in which income is insufficient my have more familial conflict, thereby hindering the support received within the family (Laursen \& Collins, 2009). It may be that since low-income adolescents have less social support opportunities, they are more likely to rate a favorite, close teacher as more supportive than an adolescent who has more relational options. Thus, given the specific questions asked in this instrument 
such as "How often do you turn to this teacher for support with personal problems?" and "How often do you depend on this teacher for help, advice, or sympathy?" it is plausible that the lack of autonomy and attachment opportunities for low-income students contributed to higher ratings of teacher support for one specific teacher. This would be different than when students rate all teachers as part of an overall measure of school climates because adolescent perceptions of teachers in general are less likely to tap into the specific emotional support they receive in individual relationships.

It is also important to understand why my hypothesis of income as a moderating factor for parental involvement was not supported. The lack of a significant moderation effect of income could also be explained by the income demographics of this sample. Again, given that the overwhelming majority of students in this sample are above the poverty level and have a high mean income, it is difficult to determine if parental involvement matters differently for children from different income brackets.

\section{Parental Involvement}

Adolescents with perceptions of higher levels of parental involvement also perceived higher levels of support from both a specific teacher (Student Teacher Relationship Quality) and from all teachers in the school (Connections with Teachers). In fact, adolescents' ratings of both maternal and paternal involvement were positively related to their ratings of teacher support. Maternal and paternal involvement explained more variance in ratings of relationship quality with one teacher than student perceptions of support from all teachers. In addition, while both maternal and paternal involvement were related to perceptions of teacher support, maternal involvement was more closely related to perceptions of both specific and overall teacher support. These findings 
contribute to research on parental involvement as previous research focused on parental involvement without distinction between parents or used measures of maternal involvement only. Results from this study suggest that the involvement of both mothers and fathers in the education of students has positive consequences for the student-teacher relationship during adolescence.

Results from this study are consistent with research that adolescents' perceptions of parental involvement are related to a higher sense of school belonging (Isakson \& Jarvis, 1999), as adolescents in this study felt more connected to teachers and care more about how teachers viewed them when they had parents who helped with homework and knew what was going on with school. Since this study used an instrument that assessed parental involvement in education at home (i.e., helps with homework and choosing coursework) and at school (i.e., goes to programs at school and watches the student in activities), findings also are congruent with those from prior parental involvement studies that demonstrate how both teacher rated parental involvement (typically school-based activities) (Wyrick \& Rudasill, 2008; Dearing, Kreider, \& Weiss, 2008) and parental involvement through academic encouragement (Chen \& Gregory, 2010) are positively related to teacher-student relationship quality.

The findings from this study also highlight the continued importance of parental support and involvement in school for outcomes in adolescents. Results suggest that while parents may have less authority concerning contemporary lifestyle choices of adolescents, their support and influence related to the future (i.e., school and career) remain of paramount importance (Laursen \& Collins, 2009). Indeed, although adolescents seek autonomy, they still need a secure attachment to and support from 
parents (McElhaney et al., 2009). Indeed, the majority of adolescents (68\%) still identity at least one parent as a primary attachment figure (i.e., the person who is contacted during emergencies and is missed most during long trips) (McElhaney et al). The research on attachment theory, coupled with the current findings on the importance of parental involvement, indicates that parents are highly valued relational figures for adolescents.

From an attachment perspective, parental involvement may become more important during high school as adolescents spend more time revising internal working models of relationships and the world (McElhaney et al.). The messages that parents send to adolescents regarding the importance of scholastic activities may be included in an adolescent's concept of how to interact with the world. The actual acts of parental involvement and the subsequent internalization of the value of education are related to the amount of support adolescents perceive from teachers. This is of particular importance because high levels of teacher support during adolescence have been linked to higher levels of academic achievement (Faircloth \& Hamm, 2005), lower drop-out rates (Davis, 2003), protection from risky health behaviors (McNeely \& Falci, 2004; Rudasill et al., 2010), lower levels of problem behaviors such as cutting class (Brewster \& Bowen, 2004), and a decrease in depressive symptoms (Ellonen, Kaariainen, \& Autio, 2008; LaRusso et al., 2008). In conclusion, results from this study support the importance of parental involvement during adolescence, specifically with regard to relationship quality with teachers.

\section{Behavioral Characteristics}

Results from the present study diverge from my hypothesis that behavioral characteristics would be negatively related to an adolescent's perception of teacher 
support. These results are surprising given that prior research has provided a wealth of support for an association between behavioral characteristics and student-teacher relationship quality. For example, internalizing problems have been linked to increased conflict (Murray \& Murray, 2004) and decreased closeness (Henricsson \& Rydell, 2004) in the student-teacher relationship and externalizing behaviors have consistently been linked to higher levels of conflict between teachers and students (Henricsson \& Rydell; Jerome et al., 2008; Justice et al., 2009; Murray \& Murray, 2004) In addition, prior research has shown that internalizing problems peak during adolescence and young adulthood (Grabery \& Sontag, 2009), suggesting that such problems should have a greater impact on perceptions of teacher support during this phase of development. A possible explanation for the inconsistency between hypothesis and results is a measurement issue. Maternal ratings of internalizing and externalizing problems were below average in this sample. Low ratings of these behavioral characteristics make it difficult to determine if higher levels of internalizing and externalizing problems are related to perceptions of teacher support. The sample also reported relatively high levels of perceived support from all teachers, with little variance. It makes it difficult to determine if externalizing and internalizing problems lower perceptions of support when perceptions are consistently high for the sample.

Finally, in this sample adolescents rated perceived levels of teacher support whereas in other research supporting a connection between student-teacher relationships and student behavioral characteristics, teachers have been the raters of relationship quality. It is plausible that ratings of externalizing and internalizing problems matter more to a teacher's perspective of conflict and closeness than to a student's perception of 
support from teachers. For example, an adolescent's social reasoning is often influenced by egocentrism (Smetana \& Villalobos, 2009). Egocentrism can manifest as the social cognitive bias of an imaginary audience in which the adolescent mistakenly believes that others are paying attention and watching him/her more closely (Smetana \& Villalobos). It is theorized that the function of the imaginary audience bias is to promote connectedness due to the decrease of identification with parents as a result of the individuation process (Smetana \& Villalobos). Social errors in thinking could explain how adolescents perceive teacher relationships as highly supportive even when they exhibit behavioral problems. For the sake of needing connection adolescents may have an imaginary audience bias and mistakenly believe that teachers are available to offer support regardless of their behaviors or mood.

Another possible theoretical explanation for the lack of significant relationships between behavioral characteristics and student-teacher relationships is again tied to the fact that adolescents rated their own perception of the relationship. Researchers have recently called attention to the need for a more thorough understanding of an adolescents' theory of mind (i.e., taking the perspective of another) development (Smetana $\&$ Villabos, 2009). Research suggests the ability to take the perspective of another continues to develop throughout adolescence and may be dependent on the environmental experiences of the adolescent (Smetana \& Villabos). For example, adolescents who have secure attachments to their parents may have more sophisticated abilities to understand another's thought processes. Other research has suggested that adolescents are more likely to express an accurate sense of what someone else is thinking if they like the individual. For example, one study found that adolescents were more accurate in taking 
the perspective of a teacher they liked than disliked (Smetana \& Villabos). Taken together, the theoretical knowledge of adolescents' ability to take perspective of another could explain why externalizing and internalizing behaviors were not related to the quality of the teacher-student relationship. It may be that adolescents have not developed the capacity to take the perspective of the teacher and realize the impact of their behaviors on the student-teacher relationship. Furthermore, given that previous research has linked higher levels of externalizing and internalizing behaviors to lower studentteacher relationship quality (Jerome et al., 2008), and this theory suggests students have a more difficult time taking the perspective of a disliked teacher (Smetana \& Villabos), it could be that the students with higher ratings of behavioral problems in this study are less likely to understand the impact they have on the teacher-student relationship, thereby inflating the rating of relationship quality.

It is also plausible that results from this study are incongruent with previous research because the measurement of student teacher relationship quality is different with younger samples. For example, the majority of research showing a negative association between student-teacher relationship quality and behavioral characteristics in elementary age students employed the Student Teacher Relationship Scale (Doumen et al., 2008; Jerome et al., 2009; Silver et al., 2005). Items that measure conflict on this scale include "Dealing with this child drains my energy" and "This child and I always seem to be struggling with each other" (Pianta, 2001). These types of questions suggest that while the teacher and child may be struggling, the teacher is also spending a significant amount of time interacting with the particular student. Indeed, it seems that children can experience both closeness and conflict in a relationship with a teacher. For example, 
Rudasill and Rimm-Kaufmann (2009) found that lower levels of shyness in a child predicted both higher levels of conflict and closeness with the teacher. It is plausible that both conflict and closeness can co-exist within the teacher-student relationship. Externalizing behaviors may indeed be related to more teacher-reported conflict in younger students, but this may not impact the overall level of perceived teacher support as rated by adolescents. It is likely that the different conceptualizations of teacherstudent relationship quality explain the divergence from my original hypothesis.

It is also important to explore why internalizing and externalizing problems were not significant moderators of parental involvement. The lack of variability in maternal ratings of internalizing and externalizing problems makes it difficult to determine if parental involvement matters differently for different levels of these problem behaviors. If the sample had more variability in regards to problem behaviors it could be more likely to determine significant moderation.

\section{Limitations}

There are several limitations in this study require further explanation. First, this study was relatively homogenous in regards to ratings of teacher support, parental involvement, and behavioral characteristics. More specifically, adolescents in this sample perceived their parents as being highly involved and teachers as being mostly supportive. Furthermore, maternal ratings of behavioral problems indicated the adolescents in this sample were below average for both internalizing and externalizing problems. The limited range for these variables likely led to an underestimation of their relationship to each other. A more heterogeneous sample would allow for a better understanding of how behavioral characteristics and parental involvement predict ratings of teacher support. 
Second, the low internal consistency (.62) of the three items taken to form the construct Connections With Teachers, poses some problems with interpretation. While Income and both Maternal Involvement and Paternal Involvement explained a greater proportion of the variance in Connection with Teachers, these results should be interpreted with caution. Given the low internal consistency, it is difficult to generalize the findings from this research to the general population. It is possible with a more reliable instrument for assessing relationships with all teachers, the discrepancy between student ratings of individual teachers and teachers as a whole could be more accurate.

Thirdly, the instrument Parental Involvement in Schooling did not provide clarification for students that may have a non-traditional family structure. The instrument asks for the student to rate involvement for the mother and father, without distinguishing what mother and father may mean to the student, such as a child who is living with the biological mother and a step-father, with the biological father not in the picture. In this scenario, researchers cannot determine if the student filled out the instrument for the absent father or step-father. It is also unclear how a student with gay or lesbian parents would complete the involvement ratings. This student may have two parents involved, but in a lesbian household for example may only be able to rate one parent on this form. Finally, children are told to put N/A if they do not have a mother or father. This becomes problematic if the child lives with guardians who are involved in education, but cannot be rated because they are not the child's mother or father.

Finally, data collection for this study created an issue related to independence of variables. Adolescents rated both parental involvement and both forms of teacher support. Thus, there could be shared variance, which in turn has the potential to inflate 
the magnitude of the results. While this may raise some concerns regarding the results of this study, it should be noted that similar results have been found using teacher report (Wyrick. 2009) and mother report (Dearing et al., 2008) of parental involvement.

\section{Future Research and Implications}

Bronfenbrenner's bioecological model of development (Bronfenbrenner \& Morris, 1998) and attachment theory (Bowlby 1969,1982) indicate that relationships are of utmost importance for healthy development of adolescents. The bioecological model stresses the importance of relationships a child has at home and school, as well as the interplay between the two systems in development. In addition, attachment research suggests that teachers serve as a secure base which can facilitate successful adaptation to school environments (Zionts, 2005). The combination of the theoretical importance of relationships and results from this study indicate some areas for future research. Given that this study points to a relationship between parental involvement and ratings of teacher support, it would be helpful for future research to distinguish whether it is home parental involvement (i.e., helping with homework) or school parental involvement (i.e., attending school events) that matters more for predicting student-teacher relationship quality. While this study addressed both aspects in a five question survey for each parent, it would be more helpful to have an instrument targeting each aspect of parental involvement in depth. Second, the fact that maternal ratings of internalizing and externalizing problems failed to predict their perceptions of teacher support or to moderate associations between maternal and paternal involvement and teacher support warrant further research with more heterogeneous samples of adolescents. In addition, it would be helpful for future research to address the issue of a lack of independence in this 
study. This could be accomplished by having teachers rate relationship quality with adolescents or have mothers and fathers rate their level of involvement in education.

Still, results from this study provide valuable information to policy and practice within the field of education and counseling. This study highlights that gender, income, and parental involvement are all significant predictors of adolescents' perceptions of teacher support. This has important practice implications in the area of teacher preparation programs. These findings suggest that preparation programs pay special attention to the multiple factors that influence healthy adolescent development, most specifically factors associated with teacher-student relationships. One such factor of interest is parental involvement. In fact research indicates that preservice teachers are not provided with sufficient numbers and depth of parent and community involvement experiences, subsequently impeding their ability to collaborate with parents and communities when they begin teaching (Flanigan, 2007). Programs that do offer an emphasis on parental involvement practices show positive results for teachers. For example when a curriculum involves family centered practices, preservice teachers display beliefs that emphasize the value of family members in education, use more family-centered practices on the job, and more fully understand the parents' perspectives on educational practices (Murray \& Mandell, 2004).

Research suggests that preservice teacher development in the area of parental involvement should encompass the following areas: examination of the teacher's beliefs about the education process and working with families; course content that portrays diverse families; brainstorming involvement ideas across a variety of contexts (i.e., volunteering, communicating, and home activities); and fieldwork opportunities that 
include interactions with the family (Baum \& Swick, 2008; Garcia, 2004; Graue \& Brown, 2003). Furthermore, change in perservice teacher development programs requires a commitment from higher education leaders to increase professor awareness of the importance of including parental involvement material in education courses. Department leaders should work to influence faculty attitudes regarding the necessity of parental involvement practices as well as hire course instructors that believe in the importance of engaging families and communities in education (Epstein \& Sanders, 2006). It is also recommended that higher education leaders form university-school collaborations to encourage preservice teachers to apply research principles regarding parental involvement to actual practice before graduation (Epstein \& Sanders).

The present research findings also have implications for counselors working with students and families. First, it is important that school psychologists and counselors recognize the importance of teacher-student relationships and parent involvement on the emotional and academic success of students. This research supports previous literature emphasizing that in order to increase family involvement practices special attention must be paid to family circumstances (Knopf \& Swick, 2007). It is within this realm that counselors can be of utmost importance in helping parents keep their familial connections strong, help parents recognize opportunities to provide school support for the student, and identify resources that can assist with the increasing demands of family life (i.e., work and child care) (Knopf \& Swick). Counselors may also work directly with the students, providing a place of support and an opportunity for a close relationship at the school. As previous research has noted, these types of close relationships within the school, promote 
higher levels of school bonding, and subsequently more academic success (Catalano et al., 2004).

School psychologists and counselors are also in a special position to provide assistance in regards to the lack of family involvement information in pre-service teacher programs. Counselors in an education setting could provide workshops to teachers and administrators regarding knowledge of family systems, diversity, strengths, barriers to involvement, and communication strategies (Broussard, 2003). The present research findings also indicate the need for school counselors to take more active roles in working with teachers to promote efficacy beliefs related to family involvement practices and help teachers develop a more flexible understanding of the family-school partnership (i.e., more ideas for communication and invitation for parents) (Pelco \& Ries, 1999). In addition to directly assisting teachers, counselors can also be helpful in providing workshops for families on building parenting skills and creating home conditions for learning (Pelco \& Reis). Finally, counselors in an education setting are valuable catalysts in establishing healthy communication styles between teachers, administrators, and parents so as to create more effective partnerships.

The current research findings also have implications for counselors outside of the school setting. It is important for counselors working with school-age children to understand the importance of teacher-student relationships and family involvement for educational and emotional success. As many children are seen in therapy for schoolrelated concerns such as academic performance or behavioral problems, counselors can benefit from understanding how a positive relationship with a teacher can improve outcomes for the student. In addition, the counselor can also work with the family to 
promote home conditions and family norms that support the child's education. For example, if a counselor is seeing a child displaying problem behavior at school, the counselor can use the current and previous research findings to stress the importance of positive parent-school partnerships, sharing how children will internalize the value of school displayed within the home (Carlisle, Stanley, \& Kemple, 2005). Overall, when working with children and families it is important to give attention to teacher-student relationships and parent involvement practices as contributors to child development. In addition to informing teachers and counselors of best student and family practice, the relationship between parental involvement and teacher support has implications for school policy. The fact that teacher-student relationships are related to student success, and parental involvement is a known predictor of the quality of these relationships suggests schools should utilize resources to increase parental involvement. Given that involvement from both mothers and fathers predicted increased levels of perceived teacher support, schools should target both parents when seeking to enhance parental involvement activities.

Should school administrators seek ways to increase parental involvement, they should first begin by working with teachers. One framework utilized to examine parental involvement suggests that teachers are more likely to initiate involvement activities if they view their professional role as a collaborator with parents, believe they possess skills to evoke involvement, and perceive they have opportunities, support, and demand from students, families, and school administrators for these initiatives (Pelco \& Ries, 1999). More specific ways that schools can increase parental involvement is to improve staff competence by providing training that focuses on the benefits, importance, and logic of 
including parents in education (Webster, 2004). It is also important for schools to create a welcoming climate for parents and provide multiple outlets for involvement (Webster). Specific practices may include: making home visits to each family in the school; opening a family center with learning materials available for checkout; family activities that are connected to lesson plans; opening the building to community use; providing social service resources are available to families; and creating opportunities for parents and teachers to examine student work and test results together (Henderson, Mapp, Johnson, \& Davies, 2007). Additionally, research suggests that secondary schools in particular can utilize four specific components to create sustainable programs of family involvement. These include: making action teams for partnerships which are responsible for creating family involvement programs linked to school improvement goals; utilize Epstein's six types of involvement framework (parenting, communicating, volunteering, learning at home, decision making, and collaborating with the community); create action plans for involvement that are linked to school improvement plans; and complete evaluations of programs and seek ongoing improvement (Epstein, 2007). Once schools work with teachers and parents to create a welcoming and supportive environment with multiple opportunities, parental involvement will increase, thereby improving perceptions of teacher support and fostering healthy adolescent development. 


\section{REFERENCES}

Achenbach, T.M. (1991). Manual for the Child Behavior Checklist/4-18 and profile. Burlington, VT: University of Vermont, Department of Psychiatry.

Archer-Banks, D.A.M. \& Behar-Horenstein, L.S. (2008). African American parental involvement in their children's middle school experiences. The Journal of Negro Education, 77, 143-156.

Baker, J.A. (2006). Contributions of teacher-child relationships to positive school adjustment during elementary school. Journal of School Psychology, 44, 211229.

Baker, J.A., Grant, S., Morlock, L. (2008). The teacher-student relationship as a developmental context for children with internalizing or externalizing behavioral problems. School Psychology Quarterly, 23 (1), 3-15.

Barnard, W.M. (2004). Parent involvement in elementary school and educational attainment. Children and Youth Services Review, 26, 39-62.

Baum, A.C. \& Swick, K.J. (2008). Dispositions toward families and family involvement: Supporting preservice teacher development. Early Childhood Education, 35, 579584.

Berry, D. \& O'Connor, E. (2010). Behavioral risk, teacher-child relationships, and social skill development across middle childhood: A child-by-environment analysis of change. Journal of Applied Developmental Psychology, 31, 1-14. 
Biederman, J., Hirshfeld-Beckre, D.R., Rosenbaum, J.F., Herot, C., Friedman, D., Snidman, N., Kagan, J., \& Faraone, S.V. (2001). Further evidence of association between behavioral inhibition and social anxiety in children. American Journal of Psychiatry, 158, 1673-1679.

Birch, S.H., \& Ladd, G.W. (1997). The teacher-child relationship and children's early school adjustment. Journal of School Psychology, 35(1), 61-79.

Bowlby, J. (1969/1982). Attachment. New York: Basic Books, Inc.

Brewster, A.B. \& Bowen, G.L. (2004). Teacher support and the school engagement of Latino middle and high school students at risk of school failure. Child and Adolescent Social Work Journal, 21(1), 47-67.

Bronfenbrenner, U. \& Morris, P.A. (1998). The ecology of developmental processes. In R.M. Lerner (Ed.) Theoretical models of human development $\left(5^{\text {th }}\right.$ ed., Vol. 1 , pp.993-1028). New York: Wiley.

Broussard, C.A. (2003). Facilitating home-school partnerships for multiethnic families: School social workers collaborating for success. Children $\&$ Schools, 25(4), 211 222.

Burchinal, M.R., Peisner-Feinberg, E., Pianta, R., Howes, C. (2002). Development of academic skills from preschool through second grade: Family and classroom predictors of developmental trajectories. Journal of School Psychology, 40(5), 415-436.

Carlisle, E., Stanley, L., \& Kemple, K.M. (2005). Opening doors: Understanding school and family influences on family involvement. Early Childhood Education Journal, 33, 155-162. 
Castor, D.C., Bryant, D.M., Peisner-Feinberg, E., \& Skinner, M.L. (2004). Parent involvement in head start programs: The role of parent, teacher and classroom characteristics. Early Childhood Research Quarterly, 19, 413-430.

Catalano, R.F., Haggerty, K.P., Oesterle, S., Fleming, C.B., \& Hawkins, J.D. (2004). The importance to school for healthy development: Findings from the social development research group. Journal of School Health, 74(7), 252-261.

Chen, W. \& Gregory, A. (2010). Parental involvement as a protective factor during the transition to high school. The Journal of Educational Research, 103, 53-62.

Clements, M.A., Reynolds, A.J., \& Hickey, E. (2004). Site-level predictors of children's school and social competence in the Chicago child-parent centers. Early Childhood Research Quarterly, 19, 273-296.

Cohen, S., Underwood, L.G., \& Gottlieb, B.H. (2000). Social support measurement and intervention A guide for health and social scientists. New York, NY: Oxford University Press.

Cooper, H., Lindsay, J.J., \& Nye, B. (2000). Homework in the home: How student, family, and parenting-style differences relate to the homework process. Contemporary Educational Psychology, 25, 464-487.

Crosnoe, R., Johnson, M.K., \& Elder, Jr., G.H. (2004). Intergenerational bonding in school: The behavioral and contextual correlates of student-teacher relationships. Sociology of Education, 77, 60-81.

Davis, H.A., (2003). Conceptualizing the role and influence of student-teacher relationships on children's social and cognitive development. Educational Psychologist, 38(4), 207-234. 
Dearing, E., Kreider, H., Simpkins, S., \& Weiss, H.B. (2006). Family involvement in school and low-income children's literacy: Longitudinal associations between and within families. Journal of Educational Psychology, 98, 653-664.

Dearing, E., Kreider, H., \& Weiss, H.B. (2008). Increased family involvement in school predicts improved child-teacher relationships and feelings about school for lowincome children. Marriage \& Family Review, 43(3/4), 226-254.

De Civita, M., Pagani, L., Vitaro, F. \& Tremblay, R.E. (2004). The role of maternal educational aspirations in mediating the risk of income source on academic failure in children from persistently poor families. Children and Youth Services Review, 26, 749-769.

Demaray, M.K., Malecki, C.K., Rueger, S.Y., Brown, S.E. \& Summers, K.H. (2009). The role of youth's ratings of the importance of socially supportive behaviors in the relationship between social support and self-concept. Journal of Youth and Adolescence, 38, 13-28.

Deslandes, R. \& Bertrand, R. (2005). Motivation of parent involvement in secondarylevel schooling. The Journal of Educational Research, 98(3), 164-175.

Diamond, J.B. \& Gomez, K. (2004). African American parents' educational orientations: The importance of social class and parents' perceptions of schools. Education and Urban Society, 36, 383- 427.

DiLalla, L.F., Marcus, J.L., \& Wright-Phillips, M.V. (2004). Longitudinal effects of preschool behavioral styles on early adolescent school performance. Journal of School Psychology, 42, 385-401. 
Doumen, S., Verschueren, K., Buyse, E., Germeijs, V., Luyckx, K., \& Soenens, B. (2008).

Reciprocal relations between teacher-child conflict and aggressive behavior in kindergarten: A three-wave longitudinal study. Journal of Clinical Child \& Adolescent Psychology, 37(3), 588-599.

Drevets, R.K., Benton, S.L., \& Bradley, F.O. (1996). Students' perceptions of parents' and teachers' qualities of interpersonal relations. Journal of Youth \& Adolescence, $25(6), 787-802$.

DuBois, D.L., Eitel, S.K., \& Felner, R.D. (1994). Effects of family environment and parent-child relationships on school adjustment during the transition to early adolescence. Journal of Marriage and the Family, 56, 405-414.

Eccles, J.S. \& Roeser, R.W. (2009). Schools, academic motivation, and stageenvironment fit. In R.M. Lerner \& L. Steinberg (Eds.), Handbook of adolescent psychology third edition: Vol 1. Individual Bases of Adolescent Development (pp. 404-434). Hoboken, NJ: John Wiley \& Sons, Inc.

Ellonen, N., Kaariainen, J., \& Autio, V. (2008). Adolescent depression and school social support: A multilevel analysis of a Finnish sample. Journal of Community Psychology, 36(4), 552-567.

Epstein, J.L. (2007). Connections count: Improving family and community involvement in secondary schools. Principal Leadership, 8, 16-22.

Epstein, J.L. \& Sanders, M.G. Prospects for change: Preparing educators for school, family, and community partnerships. Peabody Journal of Education, 81, 81-120. 
Epstein, J.L. \& Sheldon, S.S. (2002). Present and accounted for: Improving student attendance through family and community involvement. The Journal of Educational Research, 95, 308-318.

Evans, G.W., Gonnella, C., Marcynyszyn, L.A., Gentile, L., \& Salpekar, N. (2005). The role of chaos in poverty and children's socioemotional adjustment. Psychological Science, 16(7), 560-565.

Ewing, A.R. \& Taylor, A.R. (2009). The role of child gender and ethnicity in teacherchild relationship quality and children's behavioral adjustment in preschool. Early Childhood Research Quarterly, 24, 92-105.

Faircloth, B.S. \& Hamm, J.V. (2005). Sense of belonging among high school students representing 4 ethnic groups. Journal of Youth and Adolescence, 34(4), 293-309.

Fantuzzo, J., McWayne, C., Perry, M.A., \& Childs, S. (2004). Multiple dimensions of family involvement and their relations to behavioral and learning competencies for urban, low-income children. School Psychology Review, 33, 467-480.

Farrington, D.P. (2009). Conduct disorder, aggression, and delinquency. In R.M. Lerner \& L. Steinberg (Eds.), Handbook of adolescent psychology third edition: Vol. 1. Individual basis of adolescent development. (pp. 683-722). Hoboken, NJ: John Wiley \& Sons, Inc.

Fishel, M. \& Ramirez, L. (2005). Evidence-based parent involvement interventions with school-aged children. School Psychology Quarterly, 20, 371-402. 
Flanigan, C.B. (2007). Preparing preservice teachers to partner with parents and communities: An analysis of college of education faculty focus groups. The School Community Journal, 17, 89-110.

Furman, W. (1996). The measurement of friendship perceptions: Conceptual and methodological issues. In W.M. Bukowski \& A. F. Newcomb (Eds.), The company they keep: Friendship in childhood and early adolescence (pp. 41-65). NY: Cambridge University Press.

Furman, W. \& Buhrmester, D. (1985). Children's perceptions of he personal relationships in their social networks. Developmental Psychology, 21, 1016-1022.

Garcia, D.C. (2004). Exploring connections between the construct of teacher efficacy and family involvement practices: Implications for urban teacher preparation. Urban Education, 39, 290-315.

Gershoff, E.T., Aber, J.L., Raver, C.C., \& Lennon, M.C. (2007). Income is not enough: Incorporating material hardship into models of income associations with parenting and child development. Child Development, 78(1), 70-95.

Gladstone, G.L., Parker, G.B., Mitchell, P.B., Wilhelm, K.A., \& Malhi, G.S. (2005). Relationship between self-reported childhood behavioral inhibition and lifetime anxiety disorders in a clinical sample. Depression and Anxiety, 22, 103-113.

Gonzalez-DeHass, A.R., Willems, P.P., \& Holbein, M.F.D. (2005). Examining the relationship between parental involvement and student motivation. Educational Psychology Review, 17 (2), 99-123. 
Graber, J.A., \& Sontag, L.M. (2009). Internalizing problems during adolescence. In R.M. Lerner \& L. Steinberg (Eds.), Handbook of adolescent psychology third edition: Vol 1. Individual basis of adolescent development (pp. 642- 682). Hoboken, NJ: John Wiley \& sons, Inc.

Graue, E. \& Brown, C.P. (2003). Preservice teachers notions of families and schooling. Teaching and Teacher Education, 19, 719-735.

Gregory, A. \& Ripsky, M.B. (2008). Adolescent trust in teachers: Implications for behavior in the high school classroom. School Psychology Review, 37, 337-353.

Gregory, A. \& Weinstein, R.S. (2004). Connection and regulation at home and in school: Predicting growth in achievement for adolescents. Journal of Adolescent Research, 19(4), 405-427.

Gutman, L.M. \& Midgey, C. (2000). The role of protective factors in supporting the academic achievement of poor African American students during the middle school transition. Journal of Youth and Adolescence, 29 (2), 223-248.

Hamre, B.K. \& Pianta, R.C. (2001). Early teacher-child relationships and the trajectory of children's school outcomes through eighth grade. Child Development, 72(2), 625-638.

Hamre, B.K. \& Pianta, R.C. (2005). Can instructional and emotional support in the first-grade classroom make a difference for children at risk of school failure? Child Development, 76(5), 949-967.

Henderson, A.T., Mapp, K.L., Johnson, V.R., \& Davies, D. (2007). Beyond the bake sale The essential guide to family-school partnerships. The New Press: New York, NY. 
Henricsson, L. \& Rydell, A.M. (2004). Elementary school children with behavior problems: Teacher-child relations and self-perception: A prospective study. Merrill-Palmer Quarterly, 50(2), 111-138.

Hoglund, W.L. \& Leadbeater, B.L. (2004). The effects of family, school, and classroom ecologies on changes in children's social competence and emotional and behavioral problems in first grade. Developmental Psychology, 40(4), 533-544.

Hoover-Dempsey, K.V. \& Sandler, H.M. (1995). Parental involvement in children's education: Why does it make a difference? Teachers College Record, 97(2), 310331.

Hoover-Dempsey, K.V., Walker, J.M.T., Sandler, H.M., Whetsel, D., Green, C.L., Wilkins, A.S., \& Closson, K. (2005). Why do parents become involved? Research findings and implications. The Elementary School Journal, 106, 106-130.

Hughes, J.N., Cavell, T.A., \& Willson, V. (2001). Further support for the developmental significance of the quality of the teacher-student relationship. Journal of School Psychology, 39(4), 289-301.

Hughes, J.N., Gleason, K.A., \& Zhang, D. (2005). Relationship influences on teachers' perceptions of academic competence in academically at-risk minority and majority first grade students. Journal of School Psychology, 43, 303-320.

Hughes, J.N., \& Kwok, O. (2007). Influence of student-teacher and parent-teacher relationships on lower achieving readers' engagement and achievement in the primary grades. Journal of Educational Psychology, 99(1), 39-51. 
Isakson, K. \& Jarvis, P. (1999). The adjustment of adolescents during the transition into high school: A short-term longitudinal study. Journal of Youth and Adolescence, 28, 1-26.

Jerome, E.M., Hamre, B.K. \& Pianta, R.C. (2008). Teacher-child relationships from kindergarten to sixth grade: Early childhood predictors of teacher-perceived conflict and closeness. Social Development, 18(4), 915-945.

Johnson, C., Eva, A.L., Johnson, L. \& Walker, B. (2011). Don't turn away: Empowering teachers to support students' mental health. A Journal of Educational Strategies, Issues, and Ideas, 84, 9-14.

Justice, L.M., Cottone, E.A., Mashburn, A., \& Rimm-Kaufman, S.E. (2008). Relationships between teachers and preschoolers who are at risk: Contribution of children's language skills, temperamentally based attributes, and gender. Early Education and Development, 19(4), 600-621.

Kennedy, S.J., Rapee, R.M., \& Edwards, S.L. (2009). A selective intervention program for inhibited preschool-aged children of parents with an anxiety disorder: Effects on current anxiety disorders and temperament. Journal of the American Academy of Child and Adolescent Psychiatry, 48, 602- 609.

Kesner, J.E. (2000). Teacher characteristics and the quality of the child-teacher relationships. Journal of School Psychology, 28(2), 133-149.

Knopf, H.T. \& Swick, K.J. (2007). How parents feel about their child's teacher-school: Implications for early childhood professionals. Early Childhood Education Journal, 34, 291-296. 
Kohl, G.O., Lengua, L.J., \& McMahon, R.J. (2000). Parent involvement in school: Conceptualizing multiple dimensions and their relations with family and demographic risk factors. Journal of School Psychology, 38, 501-523.

Koonce, D.A. \& Harper, Jr. W. (2005). Engaging African American parents in the schools: A community-based consultation model. Journal of Educational and Psychological Consultation, 16, 55-74.

Ladd, G.W., Birch, S.H., \& Buhs, E.S. (1999). Children's social and scholastic lives in kindergarten: Related spheres of influence? Child Development, 70(6), 13731400.

Ladd, G.W. \& Price, J.M. (1997). Predicting children's social and school adjustment following the transition from preschool to kindergarten. Child Development, $58(5), 1168-1189$.

Ladky, M. \& Peterson, S.S. (2008). Successful practices for immigrant parent involvement: An Ontario perspective. Multicultural Perspectives, 10, 82-89.

LaRusso, M.D., Romer, D., \& Selman, R.L. (2008). Teachers as builders of respectful school climates: Implications for adolescent drug use norms and depressive symptoms in high school. Journal of Youth and Adolescence, 37, 386-398.

Laursen, B. \& Collins, W.A. (2009). Parent-child relationships during adolescence. In R.M. Lerner \& L. Steinberg (Eds.), Handbook of adolescent psychology third edition: Vol 2. Contextual influences on adolescent development. (pp. 3-42). Hoboken, NJ: John Wiley \& Sons, Inc. 
Loukas, A., Ripperger-Suhler, K.G., \& Horton, K.D. (2009). Examining temporal associations between school connectedness and early adolescent adjustment. Journal of Youth and Adolescence, 38, 804-812.

McElhaney, K.B., Allen, J.P., Stephenson, J.C., \& Hare, A.L (2009). Attachment and autonomy during adolescence. In R.M. Lerner \& L. Steinberg (Eds.), Handbook of adolescent psychology third edition: Vol 1. Individual bases of adolescent development. (pp. 358-403). Hoboken, NJ: John Wiley \& Sons, Inc.

McLoyd, V.C., Kaplan, R., Purtell, K.M., Bagley, E., Hardaway, C.R., \& Smalls, C. (2009). Poverty and socioeconomic disadvantage in adolescence. In R.M. Lerner \& L. Steinberg (Eds.), Handbook of adolescent psychology third edition: Vol 2. Contextual influences on adolescent development. (pp. 444-491). Hoboken, NJ: John Wiley \& Sons, Inc.

McNeely, C. \& Falci, C. (2004). School connectedness and the transition into and out of health-risk behavior among adolescents: A comparison of social belonging and teacher support. Journal of School Health, 74(7), 284-292.

Meehan, B.T., Hughes, J.N., \& Cavell, T.A. (2003). Teacher-student relationships as compensatory resources for aggressive children. Child Development, 74(4), 11451157.

Metheny, J., McWhirter, E.H., \& O’Neil, M.E. (2008). Measuring perceived teacher support and its influence on adolescent career development. Journal of Career Assessment, 16(2), 218-237. 
Michael, S., Dittus, P., \& Epstein, J. (2007). Family and community involvement in schools: Results from the school health policies and programs study 2006. Journal of School Health, 77, 567-587.

Miedel, W. \& Reyonds, A.J. (1999). Parent involvement in early intervention for disadvantaged children: Does it matter? Journal of School Psychology, 37, 379402.

Mistry, R.S., Vandewater, E.A., Huston, A.C., \& McLoyd, V.C. (2002). Economic wellbeing and children's social adjustment: The role of family process in an ethnically diverse low-income sample. Child Development, 73(3), 935-951.

Mantzicopoulos, P. (2005). Conflictual relationships between kindergarten children and their teachers: Associations with child and classroom context variables. Journal of School Psychology, 43, 425-442.

Murray, C. \& Greenberg, M.T. (2000). Children's relationships with teachers and bonds with school: An investigation of patterns and correlates in middle childhood. Journal of School Psychology, 38(5), 423-445.

Murray, C. \& Murray, K.M. (2004). Child level correlates of teacher-student relationships: An examination of demographic characteristics, academic orientations, and behavioral orientations. Psychology in the Schools, 41(7), 751762.

Murray, C., Waas, G.A., \& Murray, K.M. (2008). Child race and gender as moderators of the association between teacher-child relationships and school adjustment. Psychology in the Schools, 45(6), 562-578. 
Murray, M. \& Mandell, C.J. (2004). Evaluation of a family-centered early childhood special education preservice model by program graduates. Topics in Early Childhood Special Education, 24, 238-249.

National Institute of Child Health and Human Development, Early Child Care Research Network (1993). The NICHD Study of early child care: A comprehensive longitudinal study of young children's lives. ERIC Document Reproduction Service, No. ED 3530870.

Nzinga-Johnson, S., Baker, J.A., \& Aupperlee, J. (2009). Teacher-parent relationships and school involvement among racially and educationally diverse parents of kindergarteners. The Elementary School Journal, 110(1), 81-91.

O'Connor, E. \& McCartney, K. (2006). Testing associations between young children's relationships with mothers and teachers. Journal of Educational Psychology, $98(1), 87-98$.

O'Connor, S. (2001). Voices of parents and teachers in a poor white urban school. Journal of Education for Students Placed At Risk, 6, 175-198.

Overstreet, S., Devine, J., Bevans, K, \& Efreom, Y. (2005). Predicting parental involvement in children's school within an economically disadvantaged African American sample. Psychology in the Schools, 42, 101-111.

Pearl, N.A. \& Bryant, D.M. (2000). Bringing reality to the table: Contributors to the lack of parent participation in an early childhood service program. Administration in Social Work, 24 (4), 21-37.

Pedhazur, E.J. (1997). Multiple regression in behavioral research explanation and Prediction, Third edition, United States: Wadsworth Thomson Learning. 
Pelco, L.E. \& Ries, R.R. (1999). Teachers' attitudes and behaviors towards family-school partnerships: What school psychologists need to know. School Psychology International, 20, 265-278.

Pianta, R. C. (1999). Enhancing relationships between children and teachers. Washington, DC: American Psychological Association.

Pianta, R. C. (2001). Student-teacher relationship scale. Lutz, FL: Psychological Assessment Resources, Inc.

Pianta, R.C., Howes, C., Burchinal, M., Bryant, D., Clifford, R., Early, D., \& Barbarin, O. (2005). Features of pre-kindergarten programs, classrooms, and teachers: Do $t$ hey predict observed classroom quality and child-teacher interactions? Applied Developmental Science, 9(3), 144-159.

Pianta, R.C., Nimetz, S.L., \& Bennett, E. (1997). Mother-child relationships, teacherchild relationships, and school outcomes in preschool and kindergarten. Early Childhood Research Quarterly, 12, 263-280.

Pianta, R.C., Steinberg, M.S., \& Rollins, K.B. (1995). The first two years of school: Teacher-child relationships and deflections in children's classroom adjustment. Development and Psychopathology, 7, 295-312.

Pianta, R.C., \& Stuhlman, M.W. (2004). Teacher-child relationships and children's success in the first years of school. School Psychology Review, 33(3), 444-458.

Pomerantz, E.M., Moorman, E.A., \& Litwack, S.D. (2007). The how, whom, and why of parents' involvement in children's academic lives: More is not always better. Review of Educational Research 77(3), 373-410. 
Reddy, R., Rhodes, J.E., \& Mulhall, P. (2003). The influence of teacher support on student adjustment in the middle school years: A latent growth curve study. Development and Psychopathology, 15, 119-138.

Resnick, M.D., Bearman, P.S., Blum, R.W., Bauman, K.E., Harris, K.M., Jones, J., Tabor, J., Beuhring, T., Sieving, R.E., Shew, M., Ireland, M., Bearinger, L.H., \& Udry, J.R. (1997). Protecting adolescents from harm: Findings from the national longitudinal study on adolescent health. Journal of American Medical Association, 278(10), 823-832.

Rimm-Kaufman, S.E. \& Pianta, R.C. (2000). An ecological perspective on the transition to kindergarten: A theoretical framework to guide empirical research. Journal of Applied Developmental Psychology, 21(5), 491-511.

Rudasill, K.M. (2011). Child temperament, teacher-child interactions, and teacher-child relationships: A longitudinal investigation from first to third grade. Early Child Research Quarterly, 26, 147-156.

Rudasill, K.M., Reio, T.G., Stipanovic, N., \& Taylor, J.E. (2010). A longitudinal study of student-teacher relationship quality, difficult temperament, and risky behavior from early childhood to adolescence. Journal of School Psychology.

Rudasill, K.M., Rimm-Kaufman, S.E., Justice, L.M., \& Pence, K. (2006). Temperament and language skills as predictors of teacher-child relationship quality in preschool. Early Education and Development, 17(2), 271-291.

Rudasill, K.M. \& Rimm-Kaufman, S.E. (2009). Teacher-child relationships quality: The roles of child temperament and teacher-child interactions. Early Childhood Research Quarterly, 24, 107-120. 
Rydell, A.M., Bohlin, G., \& Thorell, L.B. (2005). Representations of attachment to parents and shyness as predictors of children's relationships with teachers and peer competence in preschool. Attachment \& Human Development, 7(2), 187-204.

Saft, E.W. \& Pianta, R.C. (2001). Teachers' perceptions of their relationships with students: Effects of child age, gender, and ethnicity of teachers and children. School Psychology Quarterly, 16(2), 123-141.

Sanders, M.G., Epstein, J.L., \& Connors-Tadros, L. (1999). Family partnerships with high schools: The parents' perspective. Retrieved from ERIC database. (ED4281480).

Seccombe, K. (2000). Families in poverty in the 1990s: Trends, causes, consequences, and lessons learned. Journal of Marriage and the Family, 62(4), 1094-1113.

Senechal, M. (2006). Testing the home literacy model: Parent involvement in kindergarten is differentially related to grade 4 reading comprehension, fluency, spelling, and reading for pleasure. Scientific Studies of Reading, 10, 59-87.

Sheldon, S. (2002). Parents' social networks and beliefs as predictors of parent involvement. The Elementary School Journal, 102, 301-316.

Silver, R.B., Measelle, J.R., Armstrong, J.M., \& Essex, M.J. (2005). Trajectories of classroom externalizing behavior: Contributions of child characteristics, family characteristics, and the teacher-child relationship during the school transition. Journal of School Psychology, 43, 39-60. 
Smetana, J.G., \& Villalobos, M. (2009). Social cognitive development in adolescence. In R.M. Lerner \& L. Steinberg (Eds.), Handbook of adolescent psychology third edition: Vol 1. Individual bases of adolescent development. (pp. 187-228). Hoboken, NJ: John Wiley \& Sons, Inc.

Steinberg, L., Brown, B., \& Dornbushc, S. (1996). Beyond the classroom: Why school reform has failed and what parents need to do. New York: Simon \& Schuster.

Stuhlman, M.W. \& Pianta, R.C. (2001). Teachers' narratives about their relationships with children: Associations with behavior in classrooms. School Psychology Review, 31(2), 148-163.

Suldo, S.M., Friedrich, A.A., White, T., Farmer, J., Minch, D. \& Michalowski, J. (2009). Teacher support and adolescents' subjective well-being: A mixed-methods investigation. School Psychology Review, 38, 67-85.

Turney, K. \& Kao, G. (2009). Barriers to school involvement: Are immigrant parents disadvantaged? The Journal of Educational Research, 102, 257-271.

U.S. Department of Commerce, Economics and Statistics Administration, U.S. Census Bureau. (2006) Income, earnings, and poverty data from the 2006 American community survey. Retrieved from http:/www.census.gov/prod/2007pubs/acs08.pdf.

U.S. Department of Health and Human Services, Assistant Secretary for Planning and Measurement .(2006). The 2006 HHS poverty guidelines. Retrieved from http://aspe.hhs.gov/poverty/06poverty.shtml. 
Van Ryzin, M.J., Gravely, A.A., \& Roseth, C.J. (2009). Autonomy, belongingness, and engagement in school as contributors to adolescent psychological well-being. Journal of Youth and Adolescence, 38, 1-12.

Vieno, A., Perkins, D.D., Smith, T.M., \& Santinello, M. (2005). Democratic school climate and sense of community in school: A multilevel analysis. American Journal of Community Psychology, 36, 327-341.

Votruba-Drzal, E. (2003). Income changes and cognitive stimulation in young children's home learning environments. Journal of Marriage and Family, 65, 341-355.

Wang, M.T., Selman, R.L., Dishion, T.J., \& Stormshak, E.A. (2010). A Tobit Regression Analysis of the Covariation Between Middle School Students' Perceived School Climate and Behavioral Problems. Journal of Research on Adolescence, 20, 274286.

Watkins, T.J. (1997). Teacher communications, child achievement, and parent traits in parent involvement models. The Journal of Educational Research, 91, 3-14.

Webster, K. (2004). No parent left behind: Evaluating programs and policies to increase parental involvement. Harvard Journal of African American Policy, 10, 117-126.

Weinraub (1996). Characteristics of infant child care: Factors contributing to positive caregiving. Childhood Research Quarterly, 11, 269-306

Wentzel, K.R., Battle, A., Russell, S.L., \& Looney, L.B. (2010). Social supports from teachers and peers as predictors of academic and social motivation. Contemporary Educational Psychology, 35, 193-202. 
Wyrick, A.J. \& Rudasill, K.M. (2009). Parent involvement as a predictor of teacherchild relationship quality in third grade. Early Education \& Development, 20(5), 845-864.

Xu, N. \& Corno, L. (2003). Family help and homework management reported by middle school students. The Elementary School Journal, 103(5), 503-517.

Yeung, R. \& Leadbeater, B. (2010). Adults make a difference: The protective effects of parent and teacher emotional support on emotional and behavioral problems of peer-victimized adolescents. Journal of Community Psychology, 38, 80-98.

Yeung, W.J., Linver, M.R., \& Brooks-Gunn, J. (2002). How money matters for young children's development: Parental investment and family processes. Child Development, 73(6), 1861-1879.

Zionts, L.T. (2005). Examining Relationships between students and teachers. In K.A. Kerns \& R.A. Richardson (Eds.), Attachment in Middle Childhood (pp. 231-254). New York, NY: Guilford Press. 
Table 1

Means and Standard Deviations for Study Variables

\begin{tabular}{llll}
\hline Variable & M & SD & Range \\
\hline Income & 108,957 & 114,759 & $2500-1,000,001$ \\
MI & 1.48 & .42 & $0-2$ \\
PI & 1.28 & .48 & $0-2$ \\
EP & 44.94 & 10.27 & $32-94$ \\
IP & 46.32 & 9.80 & $31-83$ \\
STRQ & 2.43 & .72 & $1-5$ \\
CWT & 3.18 & .68 & $1-4$ \\
\hline
\end{tabular}

*Abbreviations for table are as follows: Maternal Involvement, Paternal Involvement (PI), Externalizing Problems (EP), Internalizing Problems (IP), Student Teacher Relationship Quality (STRQ), and Connections with Teachers (CWT). 
Table 2

Intercorrelations for relations between Student Variables and Teacher Relationship Quality

\begin{tabular}{|c|c|c|c|c|c|c|c|c|}
\hline Variable & 1 & 2 & 3 & 4 & 5 & 6 & 7 & 8 \\
\hline 1.Income & -- & .044 & $.120^{* *}$ & $.154^{* *}$ & $-.097 * *$ & $* .097 * *$ & $* .081^{*}$ & $.101^{* *}$ \\
\hline 2. Gender & .044 & -- & .005 & -.026 & .039 & .046 & .068 & $.099 * *$ \\
\hline 3. MI & $.120^{* *}$ & .005 & - & $.584^{* *}$ & $-.132 * *$ & *-.080* & $.204^{* *}$ & $.383^{* *}$ \\
\hline 4. PI & $.154^{* *}$ & -.026 & $.584^{* *}$ & -- & $-.166^{* *}$ & *-.096** & $* .141 * *$ & $.319^{* *}$ \\
\hline 5. EP & $-.097^{* *}$ & *.039 & $-.132 * *$ & * $-.166^{*}$ & * $\quad-$ & $.592 * *$ & .057 & $-.077^{*}$ \\
\hline 6. IP & $-.097 * *$ & *. .046 & $-.080 *$ & $-.096 * *$ & $* .592 * *$ & -- & .041 & -.0009 \\
\hline 7. STRQ & $-.081^{*}$ & .068 & $.204 * *$ & $.141^{* *}$ & .057 & .041 & -- & $.423^{* *}$ \\
\hline 8. CWT & $.101^{* *}$ & $.099 * *$ & $.383 * *$ & $.319 * *$ & $-.077^{*}$ & -.0009 & $.423^{* *}$ & -- \\
\hline
\end{tabular}

*Abbreviations for table are as follows: Maternal Involvement, Paternal Involvement (PI), Externalizing Problems (EP), Internalizing Problems (IP), Student Teacher Relationship Quality (STRQ), and Connections with Teachers (CWT). 
Table 3

Hierarchical Regression Analyses Predicting Student Teacher Relationship Quality From Gender, Income, and Parental Involvement

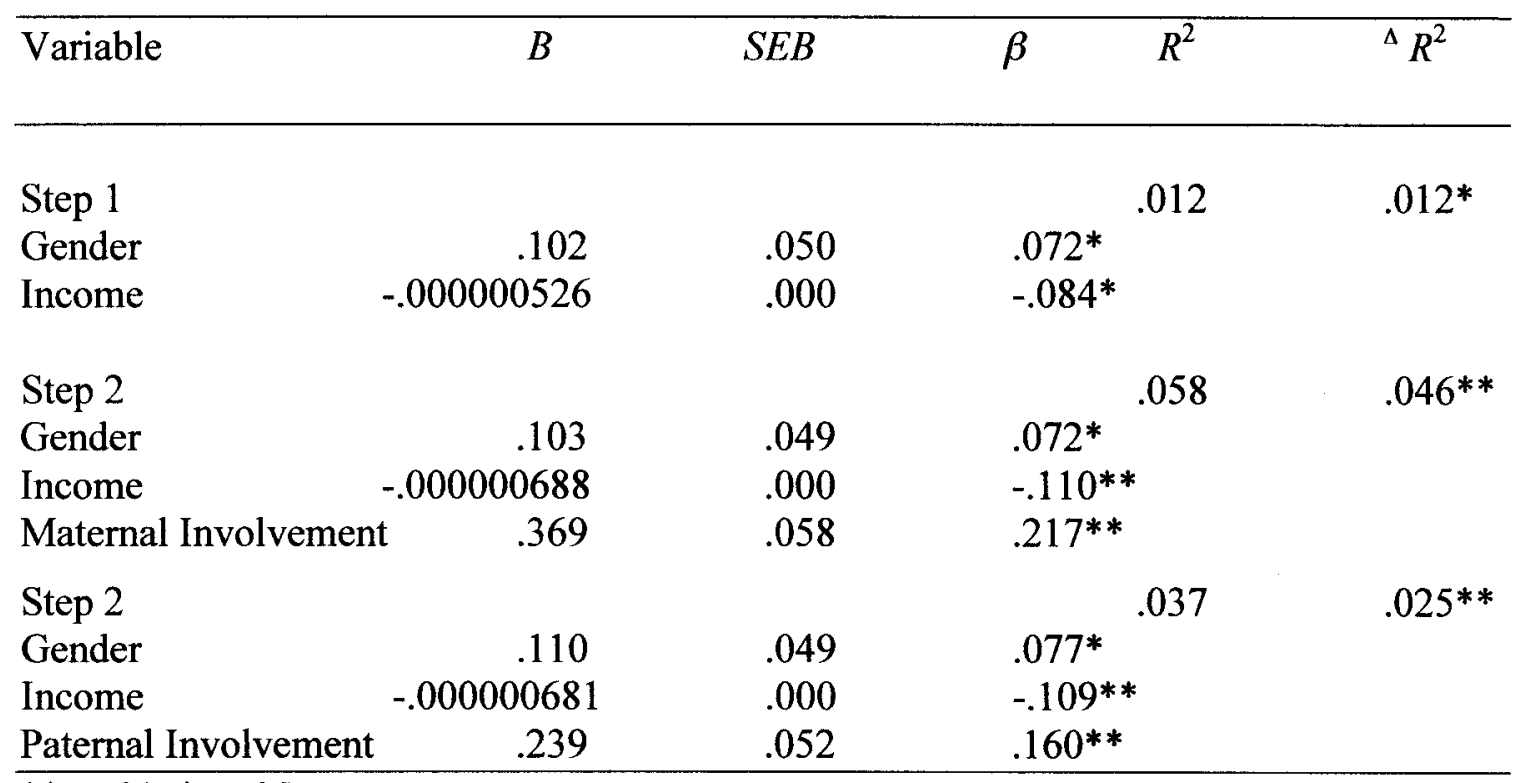

${ }^{* *} \mathrm{p}<.01,{ }^{*} \mathrm{p}<.05$ 
Table 4

Hierarchical Regression Analyses Predicting Connections with Teachers From Gender, Income, and Parental Involvement

\begin{tabular}{|c|c|c|c|c|c|}
\hline Variable & $B$ & $S E B$ & $\beta$ & $R^{2}$ & ${ }^{\Delta} R^{2}$ \\
\hline Step 1 & & & & .019 & $.019^{* *}$ \\
\hline Gender & .128 & .047 & $.095^{* *}$ & & \\
\hline Income & .0000005724 & .000 & $.097 * *$ & & \\
\hline Step 2 & & & & .159 & $.140^{* *}$ \\
\hline Gender & .128 & .044 & $.095^{* *}$ & & \\
\hline Income $\quad .0$ & .0000003064 & .000 & .052 & & \\
\hline Maternal Involvement & $\mathrm{t} \quad .606$ & .052 & $.376^{* *}$ & & \\
\hline Step 2 & & & .116 & & $.097 * * *$ \\
\hline Gender & .142 & .045 & $.105^{* *}$ & & \\
\hline Income $\quad .0$ & .0000002833 & .000 & .048 & & \\
\hline Paternal Involvement & .445 & .047 & $.315^{* *}$ & & \\
\hline
\end{tabular}

${ }^{* *} \mathrm{p}<.01,{ }^{*} \mathrm{p}<.05$ 
Table 5

Hierarchical Regression Analyses Predicting Student Teacher Relationship Quality From Gender, Income, Internalizing, and Externalizing Problems

\begin{tabular}{|c|c|c|c|c|c|}
\hline Variable & $B$ & $S E B$ & $\beta$ & $R^{2}$ & ${ }^{\Delta} R^{2}$ \\
\hline Step 1 & & & & .012 & $.012^{*}$ \\
\hline Gender & .102 & .050 & $.072 *$ & & \\
\hline Income & -.0000005263 & .000 & $-.084^{*}$ & & \\
\hline Step 2 & & & & .013 & .001 \\
\hline Gender & .100 & .050 & $.070^{*}$ & & \\
\hline Income & -.0000005078 & .000 & $-.084^{*}$ & & \\
\hline Internalizing Problems & .002 & .003 & .030 & & \\
\hline Step 2 & & & & .013 & .002 \\
\hline Gender & .100 & .050 & $.070^{*}$ & & \\
\hline Income & -.000000484 & .000 & $-.078^{*}$ & & \\
\hline Externalizing Problems & .003 & .002 & .042 & & \\
\hline
\end{tabular}

$* * p<.01, * p<.05$ 
Table 6

Hierarchical Regression Analyses Predicting Connection with Teachers From Gender, Income, Internalizing, and Externalizing Problems

\begin{tabular}{|c|c|c|c|c|c|}
\hline Variable & $B$ & $E B$ & $\beta$ & $R^{2}$ & ${ }^{\Delta} R^{2}$ \\
\hline $\begin{array}{l}\text { Step } 1 \\
\text { Gender } \\
\text { Income }\end{array}$ & $\begin{array}{l}.128 \\
.0000005724\end{array}$ & $\begin{array}{l}.047 \\
.000\end{array}$ & $\begin{array}{l}.095^{*} \\
.097^{*}\end{array}$ & .019 & $.019 * *$ \\
\hline $\begin{array}{l}\text { Step } 2 \\
\text { Gender } \\
\text { Income } \\
\text { Internalizing Problem }\end{array}$ & $\begin{array}{l}.128 \\
.0000005701 \\
.000\end{array}$ & $\begin{array}{l}.047 \\
.000 \\
.002\end{array}$ & $\begin{array}{l}.095^{*} \\
.097^{*} \\
-.004\end{array}$ & .019 & .000 \\
\hline $\begin{array}{l}\text { Step } 2 \\
\text { Gender } \\
\text { Income } \\
\text { Externalizing Problems }\end{array}$ & $\begin{array}{l}.132 \\
.0000005083 \\
-.004\end{array}$ & $\begin{array}{l}.047 \\
.000 \\
.002\end{array}$ & $\begin{array}{l}.098^{*} \\
.086^{*} \\
-.067\end{array}$ & .024 & .004 \\
\hline
\end{tabular}

${ }^{* *} \mathrm{p}<.01,{ }^{*} \mathrm{p}<.05$ 
Table 7

Hierarchical Regression Analyses Predicting Student Teacher Relationship Quality From Gender, Income, Maternal Involvement, and Behavioral Characteristics

\begin{tabular}{|c|c|c|c|c|c|}
\hline Variable & $B$ & $S E B$ & $\beta$ & $R^{2}$ & ${ }^{\wedge} R^{2}$ \\
\hline Step 1 & & & & .012 & $.012 *$ \\
\hline Gender & $\begin{array}{r}.102 \\
\end{array}$ & .050 & $.072^{*}$ & & \\
\hline Income & -.0000005263 & .000 & $-.084^{*}$ & & \\
\hline
\end{tabular}

Step 2

Gender

Income

Maternal Involvement

Internalizing Problems

Step 3

Moderation

Maternal*Internalizing $\quad .004$

Step 2

Gender

Income

.098

Maternal Involvement

$-.0000006257$

Externalizing Problems

.382

.005

Step 3

Moderation

Maternal*Externalizing

.003
.049

.000

.058

.003

.006

.049

.000

.058

.002

.063

.005

.061

.119

.069

$-.100 * *$

$.225^{* *}$

.068

.063

$.069^{*} .060$
$-.106^{* *}$
$.220^{* *}$
.045

.000

$.051^{* *}$

$.048^{* *}$

.05

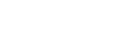

$x^{2}$

.000

${ }^{* *} \mathrm{p}<.01,{ }^{*} \mathrm{p}<.05$ 
Table 8

Hierarchical Regression Analyses Predicting Student Teacher Relationship Quality From Gender, Income, Paternal Involvement, and Behavioral Characteristics

\begin{tabular}{|c|c|c|c|c|}
\hline Variable & $B$ & $S E B$ & $R^{2}$ & ${ }^{\Delta} R^{2}$ \\
\hline Step 1 & & & .012 & $.012^{*}$ \\
\hline Gender & .102 & .050 & $.072^{*}$ & \\
\hline Income & 0005263 & .000 & $-.084^{*}$ & \\
\hline Step 2 & & & .039 & $.027 * *$ \\
\hline Gender & .107 & .049 & $.075^{*}$ & \\
\hline Income & 006585 & .000 & $-.106 * *$ & \\
\hline Paternal Involvement & .244 & .052 & $.164^{* *}$ & \\
\hline Internalizing Problems & .003 & .003 & .043 & \\
\hline $\begin{array}{l}\text { Step } 3 \\
\text { Moderation }\end{array}$ & & & .039 & .000 \\
\hline Paternal*Internalizing & .001 & .005 & -.023 & \\
\hline Step 2 & & & .041 & $.029 * *$ \\
\hline Gender & .106 & .049 & $.074^{*}$ & \\
\hline Income $\quad-.00$ & 006241 & .000 & $-.100 * *$ & \\
\hline Paternal Involvement & .253 & .052 & $.170^{* *}$ & \\
\hline Externalizing Problems & .005 & .002 & .066 & \\
\hline $\begin{array}{l}\text { Step } 3 \\
\text { Moderation }\end{array}$ & & & .041 & .000 \\
\hline$\overline{\text { Paternal*Externalizing }}$ & .003 & .005 & .093 & \\
\hline
\end{tabular}

${ }^{* *} \mathrm{p}<.01,{ }^{*} \mathrm{p}<.05$ 
Table 9

Hierarchical Regression Analyses Predicting Connection with Teachers From Gender, Income, Maternal Involvement, and Behavioral Characteristics

\begin{tabular}{|c|c|c|c|c|c|}
\hline Variable & $B$ & $S E B$ & $\beta$ & $R^{2}$ & ${ }^{\Delta} R^{2}$ \\
\hline Step 1 & & & & .019 & $.019^{* *}$ \\
\hline Gender & .128 & .047 & $.095^{*}$ & & \\
\hline Income & 005724 & .000 & $.097^{*}$ & & \\
\hline Step 2 & & & & .159 & $.140^{* *}$ \\
\hline Gender & .127 & .044 & $.094 * *$ & & \\
\hline Income $\quad .00$ & 003183 & .000 & .054 & & \\
\hline Maternal Involvement & .608 & .052 & $.378 * *$ & & \\
\hline Internalizing Problems & .002 & .002 & .022 & & \\
\hline $\begin{array}{l}\text { Step } 3 \\
\text { Moderation }\end{array}$ & & & & .162 & .003 \\
\hline$\overline{\text { Maternal x Internalizing }}$ & .009 & .005 & .304 & & \\
\hline Step 2 & & & & .159 & $.140 * *$ \\
\hline Gender & .130 & .044 & $.096^{* *}$ & & \\
\hline Income $\quad .00$ & 002855 & .000 & .048 & & \\
\hline Maternal Involvement & .601 & .052 & $.374 * *$ & & \\
\hline Externalizing Problems & -.002 & .002 & -.024 & & \\
\hline $\begin{array}{l}\text { Step } 3 \\
\text { Moderation }\end{array}$ & & & & .160 & .001 \\
\hline$\overline{\text { Maternal*Externalizing }}$ & .005 & .005 & .160 & & \\
\hline
\end{tabular}

${ }^{* *} \mathrm{p}<.01,{ }^{*} \mathrm{p}<.05$ 
Table 10

Hierarchical Regression Analyses Predicting Connection with Teachers From Gender, Income, Paternal Involvement, and Behavioral Characteristics

\begin{tabular}{|c|c|c|c|c|c|}
\hline Variable & $B$ & $S E B$ & $\beta$ & $R^{2}$ & ${ }^{\Delta} R^{2}$ \\
\hline Step 1 & & & & .019 & $.019 * *$ \\
\hline Gender & .128 & .047 & $.095^{*}$ & & \\
\hline Income & 000005724 & .000 & $.097^{*}$ & & \\
\hline Step 2 & & & & .116 & $.097^{* *}$ \\
\hline Gender & .141 & .045 & $.104 * *$ & & \\
\hline Income $\quad .00$ & 000002943 & .000 & $.050^{*}$ & & \\
\hline Paternal Involvement & .447 & .047 & $.316^{* *}$ & & \\
\hline Internalizing Problems & -.001 & .002 & .022 & & \\
\hline $\begin{array}{l}\text { Step } 3 \\
\text { Moderation }\end{array}$ & & & & .117 & .001 \\
\hline Paternal*Internalizing & .003 & .005 & .125 & & \\
\hline Step 2 & & & & .116 & $.097 * *$ \\
\hline Gender & .143 & .045 & $.106^{* *}$ & & \\
\hline Income $\quad .00$ & 000002648 & .000 & .045 & & \\
\hline Paternal Involvement & .440 & .048 & $.311^{* *}$ & & \\
\hline Externalizing Problems & -.001 & .002 & -.023 & & \\
\hline $\begin{array}{l}\text { Step } 3 \\
\text { Moderation }\end{array}$ & & & & .117 & .001 \\
\hline Paternal*Externalizing & .002 & .004 & .118 & & \\
\hline
\end{tabular}

${ }^{*}{ }^{*} \mathrm{p}<.01,{ }^{*} \mathrm{p}<.05$ 
Table 11

Hierarchical Regression Analyses Predicting Student Teacher Relationship Quality From Gender, Income, Parental Involvement, and Income

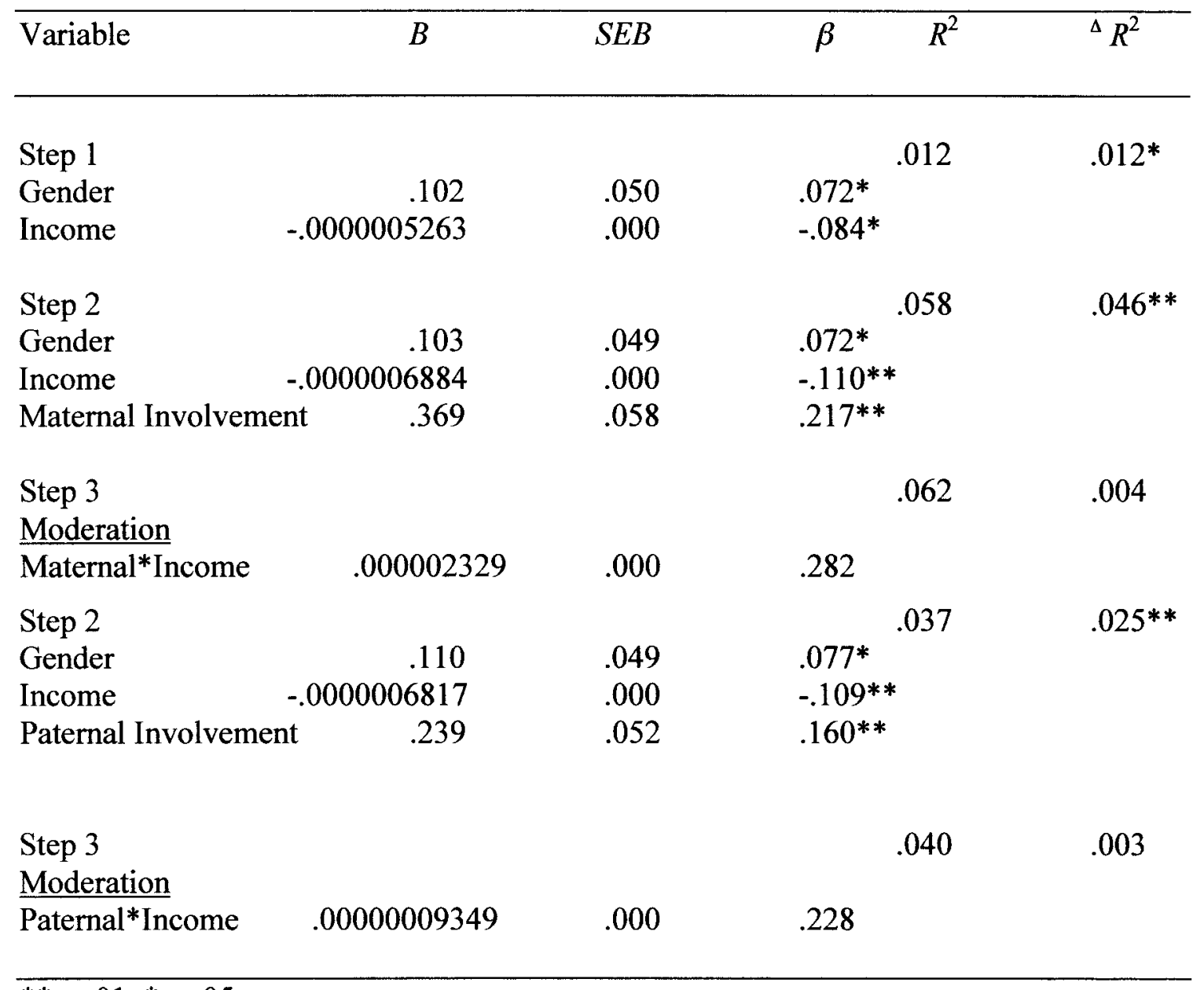

$* * p<.01, * p<.05$ 
Table 12

Hierarchical Regression Analyses Predicting Connection with Teachers From Gender, Income, Parental Involvement, and Income

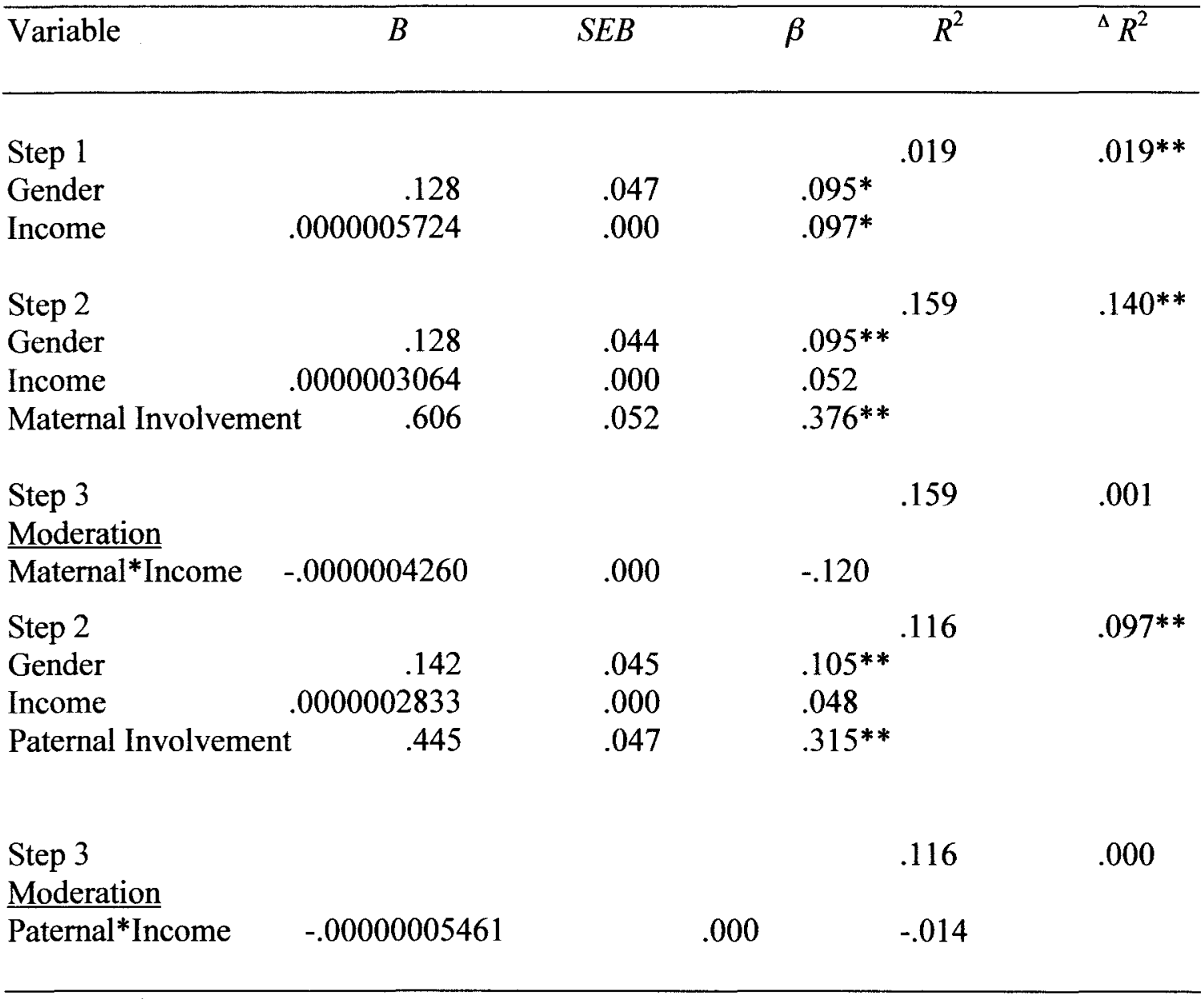

${ }^{* *} \mathrm{p}<.01,{ }^{*} \mathrm{p}<.05$ 


\section{CURRICULUM VITAE}

\section{Amanda J. Wyrick}

Address:

960 Roberson $\mathrm{St}$

Columbus, OH 43201
Phone: (502) 548-3285

wyrick.16@osu.edu

ajw6481@hotmail.com

\section{Education}

\section{August 2011}

University of Louisville, Louisville, KY

Doctoral Candidate

Dissertation topic: The influence of parent involvement and behavioral characteristics on teacher-student relationships during adolescence.

December 2006

University of Louisville, Louisville, KY

M.Ed, Counseling and Personnel Services with a concentration in Counseling Psychology

May 2003

Bellarmine University, Louisville, KY

B.A., Psychology and Sociology, summa cum laude

\section{Teaching Experience}

\section{Teaching Interest and Specialties}

My teaching interests center around examining fundamental elements of psychology as they apply to real world experiences. I am particularly interested in examining elements of diversity, social justice, mindfulness, feminist perspective, and relational bonding. I strive to accomplish learning in these areas by encouraging relationships with and between students, using active learning strategies, communicating high expectations, and respecting diverse talents and ways of learning.

\section{Courses Taught}

Adjunct Lecturer, Introduction to Psychology, Bellarmine University, Fall 2009. Adjunct Lecturer, Mind and Body Seminar, Bellarmine University, Fall 2009. Adjunct Lecturer, Characteristics, Needs, and Responses of Students with Emotional and Behavioral Adjunct Lecturer, Disorders, University of Louisville, Summer 2009 


\section{Courses Taught continued}

Adjunct Lecturer, Personality, Bellarmine University, Spring 2009, Fall, 2008, Spring 2008

Adjunct Lecturer, Human Development and Learning, University of Louisville, Spring 2009, Fall 2008, Fall 2007.

\section{Research Experience}

\section{Research Interests and Specialties}

My research interest is focused on individual and contextual factors that influence student's academic outcomes. This line of research examines how parental involvement and student characteristics (i.e., income, gender, and behavioral characteristics) impact the degree of bonding with teachers. My research thus far has examined elementary and high school age students.

\section{Research Teams}

Research Team Member- Dr. Kathleen Rudasill, University of Louisville, 2007-2010. Research interests: Parent involvement in education, teacher-student relationships, attachment, emotional functioning of adolescents

Research Team Member- Dr. Patrick Hardesty, University of Louisville, 2004-2005. Research interests: Program evaluation, career exploration

\section{Research Positions}

\section{August 2006- July 2009}

Graduate Research Assistant, Department of Teaching and Learning, University of Louisville, Louisville, KY.

- Worked with Dr. Peter Alter to conduct research on functional behavioral analysis, emotional/behavioral disorders, and classroom/teaching interventions

- Reviewed literature, collected data, conducted analyses, and prepared/edited manuscripts

\section{$\underline{\text { Publications }}$}

Wyrick, A. J., \& Rudasill, K. M. (2009). Parent involvement as a predictor of teacherchild relationship quality in third grade. Early Education and Development, 20(5), 845-864.

Alter, P.J., Wyrick, A., Brown, E.T. \& Lingo, A.S. (2008). A Novel Intervention for Improving Math Problem Solving Skills for Students with Challenging Behavior: A Pilot Study. Beyond Behavior, 17(3), 2-7. 


\section{Conference Presentations}

Wyrick, A.J., \& Rudasill, K.M (2009, April). Parent involvement as a predictor of teacher-child relationship quality in third grade. Poster presented at 2009 Society for Research in Child Development Biennial Conference, Denver, CO.

Wyrick, A.J. \& Rudasill, K.M (2008, October). Parent involvement and teacherchild relationship. Poster presented at Student Presentations to NCATE: A Showcase of Excellence.

Mitchell, N. G., Wyrick, A. J., Rudasill, K. M., White, J. B. (2008, August). Anti-fat attitudes of teacher candidates: Implications for obese students. Poster presented at the 2008 American Psychological Association Annual Convention, Boston, MA

Mitchell, N. G., Wyrick, A. J., Nichols, A. J., Carrier, J. W., Banister, A. B. (2008, August). Social stigmatization of obesity in African American preschool children. Poster presented at the 2008 American Psychological Association Annual Convention, Boston, MA.

Mitchell, N. G., Wyrick, A. J., Rudasill, K. M., \& White, J. B. (2008, March). Understanding pre-service teachers' biases: Implications for the well-being of obese students. Paper presented at the American Educational Research Association annual conference. New York, NY.

Mitchell, N. G., Wyrick, A. J., Rudasill, K. M., \& White, J. B. (2008, February). Teacher candidates and anti-fat attitudes: Are teachers susceptible to biases based on body type? Paper presented at the 2008 Association of Teacher Educators Annual Conference. New Orleans, LA.

Wyrick, A.J., \& Alter, P. (2007, October). A novel intervention for improving mathematics problem solving skills for students with challenging behavior: A pilot study. Teacher Quality Summit, Louisville, KY.

Wyrick, A.J., Mitchell, N.G., White, J.M., \& Rudasill, K.M. (2007, April). Antifat attitudes of teacher candidates. Paper session presented at the Spring Research Conference, Lexington, KY.

Vanderharr, J., Crawford, F., Wyrick, A.J., White, J.M., \& Rollins, I. (2007, April). Assessing

graduate student and faculty perceptions of diversity in an urban/metropolitan college of education. Paper session presented at the Spring Research Conference, Lexington, KY.

White, J.M., Mitchell, N.G., Wyrick, A.J., \& Rudasill, K.M. (2007, April). Pre-service teacher's attitudes towards obesity: Implications for obese children in the classroom. Poster session presented at the Kentucky Psychological Association Spring Academic Conference, Lexington, KY.

\section{University Service}

Doctoral Student Organization, President, 2006- 2008

Graduate Student Association, ECPY Representative, 2006-2007 


\section{Clinical Related Experience}

\section{September 2010-Present}

Pre-Doctoral Intern, The Ohio State University, Columbus, $\mathrm{OH}$.

- Provide 12 hours of individual services each week in a college setting to students with a range of emotional diagnoses including anxiety, depression, personality disorders, eating disorders, and substance abuse.

- Provide 3 hours of group counseling for graduate students and gay men each week.

- Facilitate outreach presentations on a variety of mental health topics relevant to the college campus including body image, working with distressed students, and healthy relationships.

- Provide supervision to a practicum student

- Serve as a representative on clinical services, technology, training, and disposition committees.

\section{August 2009- July 2010}

Practicum Intern, Indiana University Southeast Counseling Center New Albany, IN.

- Counseled a caseload of college students experiencing a range of emotional concerns including coming out issues, anxiety, depression, substance abuse, sexual abuse, and relationship issues.

- Design and implement outreach activities on the college campus related to diversity, stress management, emotional functioning, and counseling services

- Design and lead a counseling group targeting resiliency and self-esteem for women and survivors of childhood abuse.

July 2009- July 2010

Intake Coordinator, The Brook Hospital Dupont, Louisville, KY.

- Conducted intake assessments with children and adults seeking psychological and chemical dependency treatment

- Facilitated appropriate referrals including both inpatient and outpatient counseling

- Conducted crisis counseling over the phone as needed

- Facilitated insurance authorizations for hospital payment and admission

May 2009- August 2009

Practicum Intern, University of Louisville Counseling Center Louisville, KY.

- Conducted psychological testing of adults to determine eligibility for disability services and accommodations on campus for learning disabilities and ADHD

- Assessment instruments included: WAIS-IV, DKEFS, Bender Visual-Motor Gestalt Test II, Woodcock Johnson Test of Achievement, IVA, and CARE. 
August 2008- July 2009

Practicum Intern, Bellarmine University Counseling Center Louisville, KY.

- Counseled a caseload of college students experiencing a range of emotional diagnoses including Adjustment Disorder, Anorexia Nervosa, Panic Disorder, Substance Abuse, and Generalized Anxiety Disorder

- Conducted outreach services on the college campus related to various topics including: cultural diversity, counseling services, stress management, anxiety and depression

May 2008- August 2008

Practicum Intern, Archdiocese of Louisville, Louisville, KY.

- Conducted psychological testing of children and adolescents to determine eligibility for classroom services including a 504 plan or additional educational accommodations such as a word processor or extra testing time

- Assessment instruments included: WISC-IV, Brown ADHD Scale, Rotters Incomplete Sentence Blanks, VMI, WIAT-II, CBCL, BASC-II, Kinetic Family Drawing Test, House-Tree-Person Test, Thematic Apperception Test

August 2007-May 2008

Practicum Intern, Seven Counties Services - Waller Therapeutic Program, Louisville, KY.

- Counseled a caseload of child and adolescent clients experiencing a wide range of emotional and behavioral diagnoses. Provide services in the school environment, collaborating with teachers and other school staff. Counseling included both individual and family sessions

- Led a therapy group for pre-adolescent boys in the classroom focusing on social skill development and anger management

August 2006- December 2006

Practicum Intern, Wellstone Regional Hospital, Jeffersonville, IN.

- Conducted psychological testing of children, adolescents, and adults to assist in diagnostic clarification and treatment planning recommendations

- Assessment instruments included: WAIS-IV, WISC-IV, WIAT-II, CBCL, WPPSI-III, BAI, BDI-II, Kinetic Family Drawing Test, Thematic Apperception Test, Adult Manifest Anxiety Sacle, Millon Adolescent Clinical Inventory, Kovac's Children's Depression Inventory, Briere Trauma Symptom Checklist, Revised Children's Manifest Anxiety Scale 
August 2005- May 2006

Practicum Intern, The Morton Center, Louisville, KY

- Counseled a caseload of adolescent and adult clients seeking chemical dependency treatment. Counseling included both individual and family sessions. Counseling focused on cognitive behavioral interventions with an emphasis on 12-step participation

- Co-led chemical dependency, codependency, and family educational groups for adolescents and adults. Groups consisted of psychoeducational materials, art therapy interventions, and process

March 2005- August 2006

Adjunctive Therapist, Seven Counties Services Acute Child Psychiatric Services, Louisville, KY.

- Assisted clients in crisis in both home and school settings

- Provided brief therapeutic interventions, such as feeling and coping skill identification, to manage the crisis

\section{Professional Affiliations}

American Psychological Association Student Affiliate 2004-2009

Division 15 (Educational Psychology) Student Affiliate 2009

Kentucky Psychological Association Student Member 2004-2009

American Educational Research Association Student Member 2007-2009

Society for Research in Child Development Student Member 2008-2009

\section{Academic Honors/Awards}

Dr. M. Celeste Nichols Professional Development Award, 2007

Faculty Merit Award in Psychology, 2003 


\section{References}

Dr. Kathleen Rudasill

University of Louisville

College of Education and Human Development

Louisville, KY 40292

(502) 852- 0627

km.rudasill@louisville.edu

Faculty Advisor

Dr. Pamela Cartor

Bellarmine University

2001 Newburg Rd.

Louisville, KY 40205

(502) 452-8188

pcartor@bellarmine.edu

Department Chair and Faculty Mentor

Dr. Michael Day

4201 Grant Line Rd.

New Albany, IN 47150

(812) 941-2244

micaday@ius.edu

Practicum Supervisor

Dr. Shonali Raney

The Ohio State University

1640 Neil Ave.

Columbus, $\mathrm{OH} 43210$

(614) 292-5766

raney.13@.osu.edu

Interim Training Director

Dr. Peter Alter

University of Louisville

Department of Teaching and Learning

Louisville, KY 40292

(502) 852-0577

peter.alter@louisville.edu

Faculty Mentor and Supervisor 